\title{
Tax evasion, firm dynamics and growth*
}

\author{
Emmanuele Bobbio ${ }^{\dagger}$ \\ Bank of Italy
}

October 19, 2016

\begin{abstract}
Italy's growth performance has been lacklustre in the last two decades. The economy has low R\&D intensity; firms are smaller and less likely to grow or exit than firms in other advanced countries; the shadow economy is large. I show how these features arise simultaneously in a Schumpeterian growth model with heterogeneous firms where the tax auditing probability increases with firm size. Tax evasion confers a cost advantage over competitors. In equilibrium, small firms invest less in innovation because growing entails a (shadow) cost of fiscal regularization. Unfair competition forces other firms to lower the mark-up they charge for their new products, reducing the incentive to innovate. Market selection is hampered, further lowering the aggregate growth rate along the extensive margin. I calibrate the model on Italian firm-level data for the period 1995-2006 and find that enforcing taxes would have increased the longrun growth rate from $0.9 \%$ to $1.1 \%$. The market share of high type firms would have been 8 percentage points higher and average firm size $25 \%$ higher. Also, I find that lowering the tax burden can have a significant impact on growth when the shadow economy is large, while the effect is negligible when taxes are enforced.
\end{abstract}

*I thank Martino Tasso, Rosaria Vega Pansini, Alfonso Rosolia, Francesca Lotti, Matteo Bugamelli, Paolo Sestito, Paolo Finaldi Russo, Silvia Magri and Claudio Michelacci for helpful discussions and comments. All remaining errors are mine. The views set out in this paper do not necessarily reflect those of the Bank of Italy.

†emmanuele.bobbio@bancaditalia.it 


\section{Introduction}

Italy has been experiencing a prolonged period of anaemic growth, even prior to onset of the financial crisis. Labor productivity per hour worked in the nonagricultural business sector has increased at an annual rate of $0.9 \%$ between 1995 and 2006. The Italian business sector is characterized by a low R\&D intensity and it is populated by a prevalence of small firms displaying a weak "up-or-out" dynamics. R\&D expenditure by private companies in Italy was approximately $0.5 \%$ of GDP (as opposed to $1.3 \%$ in France and $1.8 \%$ in the U.S.). Regarding firm demographics, businesses with fewer than 50 employees accounted for $63.5 \%$ of employment between 2001 and 2010 (35.9\% and $29.9 \%$ ); $83.4 \%$ of entering firms were still in the market after three years $(78.7 \%$ and $71.7 \%$ ) and only $3.6 \%$ of them had grown in size (4.0 and $6.2 \%)$ - Criscuolo, Gal, and Menon (2014) and, with specific regard to Italy, Manaresi (2015).

In this paper I show how tax evasion may explain these features of Italian firms along with a weak aggregate economic performance. I use a model of endogenous growth - Romer (1990), Aghion and Howitt (1992) and Grossman and Helpman (1991) - accounting for firm dynamics - Klette and Kortum (2004) and firm heterogeneity - Lentz and Mortensen (2008) and Acemoglu, Akcigit, Bloom, and Kerr (2013) - and augment it with a game of tax evasion, price, quantity and innovation decisions.

Tax evasion in Italy is high, both in absolute terms and by international comparison. According to estimates in Schneider and Enste (2000) and Schneider and Williams (2013) the size of the shadow economy in Italy stands at approximately $25 \%$ of GDP as opposed to $15 \%$ in France and $8 \%$ in the U.S.. A similar number for Italy is found by Ardizzi, Petraglia, Piacenza, and Turati (2014) using the currency demand approach and detailed cash withdrawal data. Istat (2011) reports an official estimate of around 18\% for the period 2000-2008 and $12 \%$ regarding the share of irregular workers on total employment. More recently and with reference to the period 2011-2013, official estimates have been revised downward to approximately $13 \%$ for the size of the shadow economy as a fraction of GDP and upward to $15 \%$ for the share of irregular workers - Istat (2015). Cannari and d'Alessio (2007) use survey data and find evidence that the propensity to evade taxes has increased between 1992 and 2004.

The crucial assumption underlying the results of the paper is that small firms are less likely to be monitored by the tax enforcement authority than large firms, other things equal. According to data published by the Italian Revenue Agency (IRA) the fraction of firms with a turnover above $100 \mathrm{mln}$ euros (approximately 300 employees) monitored in 2015 was $39 \%$, as opposed to $2 \%$ for sole-proprietorship and small firms - Agenzia delle Entrate (2015). Also, sole-proprietorship enterprises concealed approximately $1 / 3$ of their turnover, according to estimates by IRA based on tax audit data for the period 20072008 and corrected for possible biases due to the non-random nature of audits Ministero dell'Economia e delle Finanze (2014). Finally, the Italian economy is characterized by a remarkably high self-employment rate, $28.3 \%$ between 1995 and 2006 according to the OECD, as opposed to $9.5 \%$ in France and $7.7 \%$ in the 
U.S.. Torrini (2005) provides evidence that differences in self-employment rates across countries are partly explained by differences in tax evasion opportunities. The fundamental source of distortions in the model is that tax evasion confers a cost advantage to firms with a greater scope for evading taxes - an advantage which is greater the higher the statutory level of taxes. A small firm that innovates and grows gives up this cost advantage; thus, she incurs a shadow cost of "fiscal regularization". In addition, the "unfair competition" brought about by firms with a greater scope tax evasion forces innovative firms to lower the markup on their products. Both, the regularization cost and unfair competition reduce the incentive to innovate for incumbent firms and the aggregate rate of technological progress with it. This outcome is reinforced via two general equilibrium channels. The low innovation effort exerted by incumbent firms weakens selection and small, less productive and less innovative firms tend to stay in the market. In so doing, tax evasion also reduces the aggregate growth rate along the extensive margin, because innovative firms account for a smaller share of resources and economic output in equilibrium. Finally, the higher prevalence of small firms in equilibrium increases the degree of unfair competition in the economy. Such circularity may disrupt the growth process, when the scope for tax evasion varies significantly across differently sized firms and statutory tax rates are high. In this case the benefits from tax evasion may be large enough that incumbent firms stop innovating, there is no selection and there are no large firms in equilibrium.

I calibrate the model using statistics for the aggregate growth rate and for the size of the shadow economy in Italy over the period 1995-2006 and targeting firm demographics that I compute from micro-data. I find that enforcing taxes would have raised the growth rate permanently from 0.9 to $1.1 \%$, both by increasing individual incentives to innovate and by shifting the composition of the economy towards more innovative firms. Entry would have been lower contributing negatively to growth instead. Also, enforcing taxes would have enhanced firm dynamics: the probability of leaving the market within one year of entry would have been 1 percentage point higher; the employment growth rate of surviving firms would have increased by $2 / 3$ and mean firm size would have been a quarter higher. Enforcing taxes increases the revenue stream for the government that can cut statutory rates. This cut has a negligible effect on growth, when tax evasion has been already eliminated - consistently with mixed findings in the empirical literature regarding the relationship between taxes and growth. However, I find that when the size of the shadow economy is large instead, cutting statutory rates does boost growth, because it reduces the benefits from tax evasion: in the calibrated version of the model reducing the tax burden by 1 percentage point by cutting corporate taxes raises the long run growth rate by 4 bases points.

The paper is related to the recent body of literature that emphasizes the importance of firm heterogeneity and efficient resource allocation for the level of productivity - Bartelsman, Haltiwanger, and Scarpetta (2012), Hsieh and Klenow (2009), Restuccia and Rogerson (2008) - and its evolution over time - Acemoglu et al. (2013), Lentz and Mortensen (2008) - as well as of size related distortions 
- Guner, Ventura, and Xu (2008), Hopenhayn (2014). The literature has developed towards a more granular exploration of the sources of inefficiencies in economies with heterogeneous firms. Particular attention has been devoted to studying the role of credit frictions for the process of economic development, Buera, Kaboski, and Shin (2011), Midrigan and Xu (2014), Moll (2014). In the context of the Klette and Kortum (2004) framework, Aghion, Akcigit, Cagé, and Kerr (2016) have considered the relationship between taxation, corruption and aggregate growth when investment in a public good can improve the innovation process, while Akcigit, Alp, and Peters (2016) have analyzed how limits to delegation can help explaining differences in firm demographics between India and the U.S.. Lentz and Mortensen (2015) study optimal taxation within this framework, while Acemoglu et al. (2013) evaluate the impact of innovation policies.

The paper is organized as follows: in section 2 I outline the model, characterize the solution to the game determining price, quantity, innovation and tax evasion decisions and characterize the balance growth path equilibrium of the economy. In section 3 I discuss identification of the model parameters and outline the calibration strategy. Results are discussed in section 4 and their robustness is tested in section 5. Section 6 concludes.

\section{The model}

I extend the Schumpeterian growth model - Aghion and Howitt (1992), Grossman and Helpman (1991), Romer (1990) - with heterogeneous firms - Klette and Kortum (2004), Lentz and Mortensen (2008) - to account for tax evasion. A sketch of the basic framework is as follows: there is a representative household consuming a final good that is competitively produced by combining a continuum of intermediate products. The productivity of an intermediate product is the result of past innovations. A firm realizing an innovation prices out the producer that was supplying the previous vintage of the intermediate good and charges the final good producer a markup. The firm enters the intermediate product market if it was a potential entrant, or grows in size, if it was already an incumbent, adding a market niche to her portfolio of leading-edge technologies. Tax evasion alters competition between producers of different vintages of the same intermediate good, distorting the markup and changing the perspective gains from investing in innovation and growing.

\subsection{Final good: consumption, production}

Time is continuous, the demand side of the economy consists of a representative household supplying labor, $L$, inelastically and choosing consumption of the 
final good, $C$, and asset holdings, $H$, to maximize utility:

$$
\begin{aligned}
U_{0}\left(H_{0}\right) & =\max _{\left\{C_{t}, H_{t}\right\}_{t \geq 0}} \int_{0}^{\infty} \ln C_{t} e^{-\rho t} d t \\
\text { s.t.: } \dot{H}_{t} & =w_{t} L-P_{t} C_{t}+r_{t} H_{t}
\end{aligned}
$$

$\rho$ is time discounting and $\{w, P, r\}$ denote prices. Asset holdings consist of an exhaustive portfolio of all ownership titles of firms populating the economy, potential and incumbent. The solution to the household problem is characterized by the Euler equation:

$$
\frac{\dot{C}_{t}}{C_{t}}=r_{t}-\rho-\frac{\dot{P}_{t}}{P_{t}}
$$

The market for the final good is perfectly competitive. The production technology is Cobb-Douglas and requires a continuum of intermediate products indexed on the unit interval:

$$
\ln Y_{t}=\int_{0}^{1} \ln \left(A_{i t} x_{i t}\right) d i
$$

$x_{i}$ is the quantity of intermediate good $i$ used into production and $A_{i}$ denotes its productivity level. Profit maximization and perfect competition imply that the demand function for intermediate $\operatorname{good} i$ is equal to:

$$
x_{i t}^{d}=\frac{P_{t} Y_{t}}{\left(1+\tau_{v a}\right) p_{i t}}=\frac{1}{p_{i t}}
$$

where $p_{i}$ is the price of the intermediate good and $\tau_{v a}$ is the tax rate on value added. The second equality follows from normalizing the price of the final good so that aggregate expenditure equals $1+\tau_{v a}$ and $P Y /\left(1+\tau_{v a}\right)=1 \forall t$. Substituting (4) into (3) aggregate output can be written as:

$$
\ln Y_{t}=\ln A_{t}-\int_{0}^{1} \ln \left(p_{i t}\right) d i
$$

with:

$$
\ln A_{t} \equiv \int_{0}^{1} \ln \left(A_{i t}\right) d i
$$

\subsection{Intermediate goods: pricing, tax evasion, innovation}

The productivity of a particular intermediate good $i$ is the result of past innovations, $q_{1 i}, q_{2 i}, \ldots, q_{I_{i t} i}$, where $I_{i t}$ is the number of successive innovations realized in product line $i$ up to time $t$ :

$$
A_{i t}=\prod_{j=1}^{I_{i t}} q_{j i}
$$


Innovation is modeled as a Poisson process. The arrival probability is a function of the amount of resources invested in innovation and the incremental step, $q$, depends on the innovation capacity of the firm, which is discovered upon entry and is permanent.

The final good producer is indifferent between paying the price $\left(1+\tau_{v a}\right) p$ for vintage $I_{i t}-1$ of variety $i$ or paying the price $\left(1+\tau_{v a}\right) p q_{I_{i t} i}$ for vintage $I_{i t}$. As argued below and shown formally in appendix A, the payoff function is strictly increasing in $p$. Then, in a Stackelberg equilibrium the firm that has the know-how to produce the latest vintage, which I assume moves first and I refer to as the leader, prices out the follower and becomes the monopolist producer in market niche $i$. The firm then enters the market as the supplier of that single product line if it was a potential entrant; or grows to size $n+1$ if it was a size $n$ incumbent, $n$ denoting the number of market niches where the firm is a technological leader. Production of each variety the firm supplies is carried out at a different establishment and requires labor only, in one to one proportion. The firm must pay taxes on value added, labor, profits and turnover at rates $\tau_{v a}, \tau_{l}, \tau_{p f}$ and $\tau_{t o}$ respectively. Or it can conceal part of the output. For simplicity suppose that the establishment has an overground and an underground part, and that the firm decides the fraction of output located in the underground part, $\lambda \in[0,1]$, where it does not pay taxes. The tax enforcement authority visits the establishment with a certain probability, this probability growing with the amount of output the firm attempts to conceal and with the size of the firm: $\operatorname{Pr}^{\prime}(\lambda x \mid n)>0, \operatorname{Pr}^{\prime \prime}(\lambda x \mid n) \geq 0$ and $\operatorname{Pr}(\lambda x \mid n+1) \geq \operatorname{Pr}(\lambda x \mid n)$. Innovation is carried out in the overground section of the establishment and requires labor only. ${ }^{1}$ In the robustness section I also consider the case where innovation requires the final good instead of labor, capturing the idea that investments in goods such as ICT can raise productivity or increase the quality of the intermediate good. I assume that innovation is arbitrarily costly at a plant that has become a technological lagger. Consider a particular market niche. Let $v_{S}, S \in\{L, F\}$ be the expected value of an innovation for the leader $(L)$ and for the follower $(F)$ and $w$ be the aggregate wage level and assume that when indifferent the final good producer buys the latest vintage. Given the demand function 4 , the leader and the follower choose the price $p_{S}$, tax evasion $\lambda_{S}$ and the amount of resources to invest in innovation $\iota\left(\gamma_{S} \mid S\right)$, or equivalently

\footnotetext{
${ }^{1}$ Alternatively I could assume that a fraction $\lambda$ of the investment in innovation is concealed in the underground part of the establishment. In this case the firm pays more profit taxes but has a lower labor cost. The analysis is somewhat simplified and results are fundamentally unaffected.
} 
the innovation rate $\gamma$, to maximize the payoff function $\Omega$ :

$$
\begin{aligned}
& \Omega\left(p_{S}, \lambda_{S}, \gamma_{S} \mid n_{S}, v_{S}, S, q_{L}, p_{-S}, w\right)= \pi\left(p_{S}, x\left(p_{S}, p_{-S} \mid q_{L}\right), \lambda_{S}, \gamma_{S} \mid n_{S}, S, w\right) \\
&+\gamma_{S} v_{S} \\
& x\left(p_{L}, p_{F} \mid q_{L}\right)= \begin{cases}\frac{1}{p_{L}} & \text { if } p_{L} \leq p_{F} q_{L} \\
0 & \text { o.w. }\end{cases} \\
& x\left(p_{F}, p_{L} \mid q_{L}\right)= \begin{cases}\frac{1}{p_{F}} & \text { if } p_{F} q_{L}<p_{L} \\
0 & \text { o.w. }\end{cases}
\end{aligned}
$$

where $\pi$ is the profit flow:

$$
\begin{aligned}
\pi(p, x, \lambda, \gamma \mid n, S, w)= & \left(1-\tau_{p f} \mathbb{1}_{\Pi_{c}^{\lambda, \gamma}>0}\right) \Pi_{c}^{\lambda, \gamma}(p, x \mid S, w)-(1-\lambda) \tau_{t o} p x \\
& +\lambda \Pi_{n c}(p, x \mid w)-(1+\nu) \operatorname{Pr}(\lambda x \mid n) \Upsilon(p, x, \lambda, \gamma \mid S, w)
\end{aligned}
$$

and $\Upsilon$ is tax gap, $\nu$ is the fine the firm must pay on top of taxes if it is caught by the tax enforcement authority (in Italy the fine is indeed a proportional constant):

$$
\begin{aligned}
\Upsilon(p, x, \lambda, \gamma \mid S, w)= & \lambda\left(\tau_{v a} p x+\tau_{t o} p x+\tau_{l} w x\right) \\
& +\tau_{p r}\left[\mathbb{1}_{\Pi_{c}^{0, \gamma}>0} \Pi_{c}^{0, \gamma}(p, x \mid S, w)-\mathbb{1}_{\Pi_{c}^{\lambda, \gamma}>0} \Pi_{c}^{\lambda, \gamma}(p, x \mid S, w)\right]
\end{aligned}
$$

and $\Pi_{c}^{\lambda, \gamma}(p, x \mid S, w)$ and $\Pi_{n c}(p, x \mid w)$ are the profit flows generated in the overground (gross of turnover taxes) and in underground part of the establishment respectively - $c$ and $n c$ standing for "compliant" and "not compliant":

$$
\begin{aligned}
\Pi_{c}^{\lambda, \gamma}(p, x \mid S, w) & =(1-\lambda) \Pi_{c}(p, x \mid w)-\iota(\gamma \mid S, w) \\
\Pi_{c}(p, x \mid w) & =p x-x \varsigma_{c}(w) \\
\Pi_{n c}(p, x \mid w) & =\left(1+\tau_{v a}\right) p x-x \varsigma_{n c}(w)
\end{aligned}
$$

$\varsigma_{c}$ and $\varsigma_{n c}$ are the constant marginal costs in the overground and underground part of the establishment and are equal to $\left(1+\tau_{l}\right) w$ and $w$ respectively.

Proposition 1. The subgame perfect Nash equilibrium of the Stackelberg game where the leader and the follower have payoff functions as specified in (6) and where the tecnological leader moves first is characterized as follows:

$i$ The firm never picks a price-tax evasion combination $\left(p_{S}, \lambda_{S}\right)$ such that $\operatorname{Pr}\left(\lambda x\left(p_{S}, p_{-S} \mid q_{L}\right) \mid n_{S}\right)=1$;

ii The payoff functions of the leader $\Omega(\cdot \mid L)$ and of the follower $\Omega(\cdot \mid F)$ are strictly increasing in the price, provided that $p_{L} \leq p_{F} q_{L}$ and $p_{F} q_{L}<p_{L}$, respectively, and that the pairs $\left(p_{S}, \lambda_{S}\right), S \in\{L, F\}$ are sensible, in the sense specified in part $i$;

iii The follower chooses $\gamma_{F}=0$ and $p_{F}=p_{L} / q_{L}$ and $\lambda_{L} \in[0,1]$; 
iv The leader charges the limit price $p_{L}: \max _{\lambda} \pi\left(p_{L} / q_{L}, q_{L} x\left(p_{L}, p_{L} / q_{L} \mid q_{L}\right)\right.$, $\left.\lambda, 0 \mid n_{F}, F, w\right)=0$ and picks $(\lambda, \gamma)$ to maximize the payoff $\pi\left(p_{L}, x\left(p_{L}, p_{F} \mid q_{L}\right)\right.$ $\left., \lambda_{L}, \gamma_{L} \mid n_{F}, F, w\right)+\gamma_{L} v_{L}$.

Proof. See appendix A

A sketch of the proof follows. If the firm were to choose $(\lambda, p)$ such that $\operatorname{Pr}\left(\lambda x\left(p_{S}, p_{-S} \mid q_{L}\right) \mid n_{S}\right)=1$ then the expected cost of tax evasion would be higher than paying taxes outright and $(0, p)$ must yield a higher payoff. As for part $i i$, the result hinges on the assumption that the production function in the final good sector is Cobb-Douglas so that revenues do not depend on the price the firm charges, while production costs increase in $x$ or, equivalently, decrease in $p$ (see eq. 4) as far as $p$ is lower than the price per efficiency unit charged by the competitor. In addition, I assume that the probability that the firm is monitored and caught by the tax enforcement authority decreases the lower amount of output it conceals. This assumption is made so that the tax evasion choice always depends on the price and viceversa - see cases A and C in appendix A - and not only in marginal cases - case B. Since the payoff function increases with the price, the leader charges the maximal price such that, even if the follower tries to exploit the tax evasion margin, it cannot undercut the leader and still make a positive profits. Since I assume that the follower cost of innovation is arbitrarily large, there is no reason for it to stay in the market while earning a negative profit flow, therefore it quits market niche $i$. The price level the leader charges depends on his innovation ability captured by $q_{L}$, which allows the leader to charge a markup to the final good producer, and is constrained by the operating cost of the follower which the follower can reduce by evading taxes. Finally given the price $p_{L}$ the leader picks the combination of tax evasion rate $\lambda_{L}$ and innovation effort $\gamma_{L}$ that maximizes profits.

\subsection{Intermediate goods: values}

There are two types of firm differing in terms of their innovative capacity, $z=\epsilon$ $\{b, g\}$ with $q_{g}=q>q_{b}=1$. Type $b$ firms ("bad") are imitators, they are unable to generate improvements that actually enhance the productivity of an intermediate product, while type $g$ firms ("good") are innovators. There is a mass $m$ of potential entrants having access to the same innovation technology as incumbents, $\iota(\gamma)$. The type of a firm is realized upon entry and it is equal to $g$ with probability $\phi$ and to $b$ with probability $1-\phi$. Also, it is permanent. An incumbent firm adds to her technology portfolio by investing in innovation. Innovation is undirected and whenever a firm realizes an innovation in some market niche, some other firm is displaced from that market niche. ${ }^{2}$ Therefore,

\footnotetext{
${ }^{2}$ In facts, in the model some market niches offer a higher expected value than others. Specifically, it would be more profitable for a firm to target market niches where the leader is more intensely monitored by the tax enforcement authority. I prevent firms from doing so by assumption. The assumption can be justified to a certain extent by appealing to the uncertainty intrinsic to research effort. Also, note that relaxing it would strengthen the argument: large, more productive and more innovative firms would be targeted and be more
} 
all firms are subject to the same instantaneous probability of loosing a market niche and become an $n-1$ size firm. I denote such common destruction rate $\delta$. A firm that has one market niche and looses it exits the market.

As mentioned above the auditing probability increases with the size of the firm. In particular, I assume that a firm is more intensely scrutinized if it operates more than one plant, $\operatorname{Pr}(\lambda / p \mid 1)<\operatorname{Pr}(\lambda / p \mid n)=\operatorname{Pr}(\lambda / p \mid n+1), \forall \lambda / p>0$ and $n>$ 1 and that once a firm is subject to a high monitoring probability she remains so, even if her size subsequently drops below 2 . I refer to a firm whose size is (or has been) equal to or greater than $n=2$ as "large" and to other firms as "small" and use the letters $l$ and $s$ to indicate the degree of scrutiny a firm is subject to.

The value of a firm is the sum of the values of the establishments it operates, or equivalently of the market niches where she is a leader. ${ }^{3}$ Let $v_{z d}^{f}$ be the value of an establishment operated by a type $z \in\{b, g\}$ firm having size $d \in\{s, l\}$ and competing against a size $f \in\{s, l\}$ firm. If the firm is large, the discounted expected stream of net profits generated by an establishment is equal to:

$$
\begin{aligned}
r v_{z l t}^{f}-\dot{v}_{z l t}^{f} & =\max _{\lambda, \gamma}\left\langle\pi_{z l t}^{f}(\lambda, \gamma)+\gamma v_{z l t}-\delta v_{z l t}^{f}\right\rangle \\
v_{z l t} & \equiv \zeta_{s t} v_{z l t}^{s}+\zeta_{l t} v_{z l t}^{l}
\end{aligned}
$$

where $\zeta_{f}$ is the fraction of product market niches in the economy where the leader has size equal to $f$ and $\pi_{z l t}^{f}(\lambda, \gamma)$ is short for $\pi_{t}\left(p_{L}, 1 / p_{L}, \lambda, \gamma \mid l, z, w\right)$, given that the limit price $p_{L}$ is known from the solution to the Stackelberg game illustrated above - up to the equilibrium wage level, $w$. Profits are discounted at the nominal interest rate $r$; the flow value of the establishment net of capital gains due to the flowing of time equals net profits, plus the expected capital gains from expending into a new market niche, minus the expected capital losses from loosing the technological leadership in the market niche currently dominated by the firm. Since $v_{z l t}^{s}<v_{z l t}^{l}$, then $v_{z l t}<v_{z l t}^{l}$. Thus, the stronger

likely to be pushed out of the market than small, less productive, less innovative firms, thus increasing the shadow cost of regularization, decreasing selection and unfair competition along the extensive margin.

${ }^{3}$ I assume that each establishment pays taxes separately, that innovation is carried out at the establishment level and that innovation costs cannot be shifted from one establishment to another. A firm making negative profits at an establishment and positive profits at another establishment would have an incentive to shift innovation costs at the establishment yielding positive profits so as to decrease the overall corporate tax bill. These are cases that turns out to be irrelevant for the empirical application implemented below. Also, in the empirical application a firm with two or more product market niches exerts the same innovation effort at all establishments, regardless of follower characteristics. Therefore I could simply assume parameter values such that the equilibrium has these features and prove that the value function is modular across market niches, as in Klette and Kortum (2004) and Lentz and Mortensen (2008), rather than working at the establishment level and aggregating establishments up to the firm level. Another approach delivering the same result is to assume that profit taxes are calculated on profits gross of innovation costs, braking the direct dependence of $\gamma$ on $p$ and $\lambda$. In this case the result regarding the effect of tax evasion on aggregate growth would be fundamentally unaffected, though the counterfactual implications of changing corporate taxes might differ, as it should be clear from the analysis in appendix B for the case with no tax evasion. 
the cost advantage for the follower due to tax evasion $\left(v_{z l t}^{l}-v_{z l t}^{s}\right)$ and the more widespread tax evasion $\left(\zeta_{s}\right)$, the lower incentives to invest in innovation for large firms. I refer to the quantity $v_{z l t}^{l}-v_{z l t}$ as the "extent of unfair competition". If the firm is small and makes an innovation it grows into a 2 product lines firm, becoming large and subject to a higher degree of scrutiny by the tax enforcement authority. As a result, while the firm acquires a new market niche, she also must regularize part of her business at the plant she was already operating, which entails a shadow cost:

$$
r v_{z s t}^{f}-\dot{v}_{z s t}^{f}=\max _{\lambda, \gamma}\left\langle\pi_{z s t}^{f}(\lambda, \gamma)+\gamma\left[v_{z l}-\left(v_{z s t}^{f}-v_{z l t}^{f}\right)\right]-\delta v_{z s t}^{f}\right\rangle
$$

where $v_{z l t}^{f}-v_{z s t}^{f}>0$ follows from comparing this expression with that for a large firm and from the fact that, since a small firm is subject to lower scrutiny, it can implement the same strategy as a large firm, i.e. pick $\left(\lambda_{z l t}^{f}, \gamma_{z l t}^{f},\right)$, and still make higher profits than a large firm. I refer to the difference $v_{z l t}^{f}-v_{z s t}^{f}$ as the "regularization cost". Comparing the value function for a small and for a large firm one notices that the regularization cost reduces the expected value of an innovation. Thus, tax evasion reduces the incentives for small firms to innovate and grow in size.

A type $b$ firm, i.e. a firm such that $q_{b}=1$, makes positive profits only if she is up against a follower that is subject to stricter fiscal enforcement. If this firm innovates and grows she looses this cost advantage. Thus, she pays the regularization cost and does not rip any benefit from entering a second market niche, where she will earn zero profits at most, i.e. $\pi_{b l t}^{f}\left(\lambda_{b l t}^{f}, \gamma_{b l t}^{f}\right) \leq 0$. Therefore a type $b$ firm will always choose not to invest in innovation, $\gamma_{b d t}^{f}=0$, and to remain small. It follows that in equilibrium all large firms must be type $g$. Finally, as it is clear from the labor market clearing condition outlined below, on a balanced growth path the aggregate wage level, $w_{t}$, is constant, thus the value of a market niche is constant as well. All this considered I can rewrite the system of value functions more compactly:

$$
\begin{aligned}
v_{b}^{f} & =\frac{\pi_{b}^{f}}{\rho+\delta}, \forall f \in\{s, l\} \\
v_{g s}^{f} & =\max _{\lambda, \gamma}\left\langle\frac{\pi_{g s}^{f}(\lambda, \gamma)+\gamma\left[v_{l}-\left(v_{g s}^{f}-v_{g l}^{f}\right)\right]}{\rho+\delta}\right\rangle, \forall f \in\{s, l\} \\
v_{g l}^{f} & =\max _{\lambda, \gamma}\left\langle\frac{\pi_{g l}^{f}(\lambda, \gamma)+\gamma v_{l}}{\rho+\delta}\right\rangle, \forall f \in\{s, l\}
\end{aligned}
$$

where I renamed $v_{l}=v_{g l}$ since only type $g$ firm can be large and I have used the Euler equation from the household problem (2) which along with the normalization $P_{t} Y_{t}=1+\tau_{v a}$ implies $r=\rho$. 


\subsection{General equilibrium}

As mentioned above, there is a fix mass of potential entrants, $m$; firms in the entry pool have access to the same innovation technology as incumbents, $\iota(\gamma)$. Upon realizing an innovation the firm observes her type, $g$ with probability $\phi$ and $b$ with probability $1-\phi$, and enters the market with one product line, $n=1$. A firm in the entry pool exerts innovation effort $\gamma_{0}$ such that the marginal cost equals the expected value of entering the intermediate product market and the aggregate entry flow is $\eta=m \gamma_{0}$ :

$$
\eta=m \gamma_{0}=m \iota^{\prime-1}\left(\phi \sum_{f \in\{s, l\}} \zeta_{f} v_{g s}^{f}+(1-\phi) \sum_{f \in\{s, l\}} \zeta_{f} v_{b}^{f} \mid w\right)
$$

The aggregate destruction rate is the result of the innovation activity carried out by all firms in the economy, new entrants and incumbents, small or large:

$$
\delta=\eta+\sum_{d \in\{s, l\}} \sum_{f \in\{s, l\}} \gamma_{g d}^{f} \zeta_{g d}^{f}
$$

The steady state flow equations determining the share of types and leader and follower sizes across product lines are:

$$
\begin{aligned}
\zeta_{b}^{f}, f \in\{s, l\}: & \eta(1-\phi) \zeta_{f} & =\delta \zeta_{b}^{f} \\
\zeta_{g s}^{f}, f \in\{s, l\}: & \eta \phi \zeta_{f} & =\left(\gamma_{g s}^{f}+\delta\right) \zeta_{g s}^{f} \\
\zeta_{g l}^{f}, f \in\{s, l\}: & (\delta-\eta) \zeta_{f}+\gamma_{g s}^{f} \zeta_{g s}^{f} & =\delta \zeta_{g l}^{f}
\end{aligned}
$$

In steady state the inflow equals the outflow: the inflow of product lines supplied by type $b$ firms and competing against a follower with size $f$ equals the entry flow $\eta$ times the probability that the entering firm turns out to be type $b, 1-\phi$, times the probability that the firm ends up competing against a size $f$ follower, which is equal to $\zeta_{f}$, since innovation is undirected. With regard to $\zeta_{g s}^{f}$, the outflow is augmented with the probability that an innovation is realized and the firm becomes large, $\gamma_{g s}^{f}$. Finally, with regard to large firms, all innovation that is not realized by new entrants results in the creation of establishments owned by large firms, accruing to the stock $\zeta_{g l}^{f}$. In addition plants which were operated by small, type $g$ firms become part of a large firm further contributing to $\zeta_{g l}^{f}$.

The mass of intermediate products supplied by small type firms is equal to $\zeta_{s}=\zeta_{b}^{s}+\zeta_{b}^{l}+\zeta_{g s}^{s}+\zeta_{g s}^{l}$. Using eqs. (15a) and (15b) and $\zeta_{l}=1-\zeta_{s}-$ which follows from the fact that the measure of product lines is normalized to 1 I can express $\zeta_{s}$ as a function of rates characterizing the birth-death process $\left\{\eta, \delta, \gamma_{g s}^{s}, \gamma_{g s}^{l}\right\}$ and then solve the system of equations (15) recursively:

$$
\zeta_{s}=\frac{\eta}{\delta} \frac{\left(\gamma_{g s}^{l}+\delta\right)\left(\gamma_{g s}^{s}+\delta\right)-\phi \gamma_{g s}^{l}\left(\gamma_{g s}^{s}+\delta\right)}{\left(\gamma_{g s}^{l}+\delta\right)\left(\gamma_{g s}^{s}+\delta\right)+\phi \eta\left(\gamma_{g s}^{s}-\gamma_{g s}^{l}\right)}
$$


The wage rate must clear the labor market. Labor supply is exogenous and equal to $L$. Labor demand is the sum of labor hired for production and for innovation. One unit of labor produces one unit of output and demand for an intermediate good equals the inverse of the price, eq. (4). The price that a firm charges for an intermediate product is equal to the type specific innovation step $-q_{z}, z \in\{b, g\}$ - times the limit price that lowers the follower profits to zero see proposition 1 . This price depends on the ability of the follower to conceal production, i.e. on its size $-f \in\{s, l\}$ - and on the cost of production, $w$ (see appendix A). Labor is also used for innovation both by potential entrants and incumbents, a firm requiring $\iota(\gamma) / w$ units of labor at a plant for that plant to generate an innovation at rate $\gamma$. Thus, the equilibrium wage rate solves:

$$
L=m \frac{\iota\left(\frac{\eta}{m} \mid w\right)}{w}+\sum_{d \in\{s, l\}} \sum_{f \in\{s, l\}} \zeta_{d}^{f} \frac{\iota\left(\gamma_{g d}^{f} \mid w\right)}{w}+\sum_{z \in\{b, g\}} \sum_{f \in\{s, l\}} \zeta_{z}^{f} \frac{1}{p_{z}^{f}}
$$

Finally, from eq. (5) the aggregate growth rate is equal to:

$$
\frac{\dot{A}}{A}=\left(\eta \phi+\sum_{d \in\{s, l\}} \sum_{f \in\{s, l\}} \gamma_{g d}^{f} \zeta_{g d}^{f}\right) \ln q
$$

Definition 1. Given the normalization $P_{t} Y_{t}=1+\tau_{v a}$, a Balanced Growth Path Equilibrium consists of:

- an aggregate state $\left\{w, r,\left\{P_{t}, A_{t}\right\}_{t \geq 0}, \zeta\right\}$ characterized by a constant wage $w$, a constant interest rate $r$, a final good price sequence $\left\{P_{t}\right\}_{t \geq 0}$, a TFP sequence $\left\{A_{t}\right\}_{t \geq 0}$ and a constant vector of market niche shares $\boldsymbol{\zeta}=\left\{\zeta_{b}^{s}, \zeta_{b}^{l}\right.$, $\left.\zeta_{g s}^{s}, \zeta_{g s}^{l}, \zeta_{g l}^{s}, \zeta_{g l}^{l}\right\}$

- individual consumption $\left\{C_{t}\right\}_{t \geq 0}$ and production decisions $\left\{Y_{t}\right\}_{t \geq 0}$ by the household and by the final good producer respectively, as well as constant decisions by intermediate good producers for prices $\boldsymbol{p}=\left\{p_{b}^{s}, p_{b}^{l}, p_{g s}^{s}, p_{g s}^{l}\right.$, $\left.p_{g l}^{s}, p_{g l}^{l}\right\}$ quantities $\boldsymbol{x}=\left\{x_{b}^{s}, x_{b}^{l}, x_{g s}^{s}, x_{g s}^{l}, x_{g l}^{s}, x_{g l}^{l}\right\}$ tax evasion rates $\boldsymbol{\lambda}=$ $\left\{\lambda_{b}^{s}, \lambda_{b}^{l}, \lambda_{g s}^{s}, \lambda_{g s}^{l}, \lambda_{g l}^{s}, \lambda_{g l}^{l}\right\}$ and innovation rates $\gamma=\left\{\gamma_{b}^{s}, \gamma_{b}^{l}, \gamma_{g s}^{s}, \gamma_{g s}^{l}, \gamma_{g l}^{s}, \gamma_{g l}^{l}\right\}$ and associated values $\boldsymbol{v}=\left\{v_{b}^{s}, v_{b}^{l}, v_{g s}^{s}, v_{g s}^{l}, v_{g l}^{s}, v_{g l}^{l}\right\}$

such that:

i. given $\left\{P_{t}\right\}_{t \geq 0}$, factor demand in the final good sector is optimal, i.e. $\left\{\left\{Y_{t}\right\}_{t \geq 0}, \boldsymbol{p}, \boldsymbol{x}\right\}$ satisfy eq. (4);

ii. given $\boldsymbol{w}$ and $\boldsymbol{v}$, individual choices for $\{\boldsymbol{p}, \boldsymbol{x}, \boldsymbol{\lambda}, \boldsymbol{\gamma}\}$ sustain the the subgame perfect Nash equilibrium of the Stackelberg game, i.e. they satisfy the conditions in Proposition 1.iv;

iii. given $\{w, r, \delta, \boldsymbol{p}, \boldsymbol{x}, \boldsymbol{\lambda}, \boldsymbol{\gamma}\}$, individual values $\boldsymbol{v}$ satisfy the value functions eq. (12); 
iv. given $\{w, \boldsymbol{\zeta}, \boldsymbol{v}\}$ the innovation effort exerted by potential entrants is optimal, i.e. $\eta$ satisfies eq. (13);

$v$. given the vector of market niche shares $\boldsymbol{\zeta}$, the entry rate $\eta$ and incumbent innovation rates $\gamma$ yield the destruction rate $\delta$, i.e. eq. (14) holds;

vi. given the birth-death process as characterized by the tuple $\{\eta, \delta, \gamma\}$, the vector of market niche shares $\boldsymbol{\zeta}$ satisfies the system of stock-flow equations, eq. (15);

vii. the wage $w$ clears the labor market, i.e. $\{w, \boldsymbol{x}, \eta, \gamma\}$ satisfy eq. (16);

viii. the market for the final good clears $C_{t}=Y_{t}$ and, under the chosen normalization, $P_{t}=\left(1+\tau_{v a}\right) / Y_{t}, \forall t \geq 0$;

ix. $\left\{r,\left\{P_{t}, C_{t}\right\}_{t \geq 0}\right\}$ satisfy the Euler equation eq. (2), i.e. $r=\rho$;

x. $\left\{\left\{Y_{t}, A_{t}\right\}_{t \geq 0}, \boldsymbol{p}\right.$ satisfy eq. (5), $\left\{Y_{t}\right\}_{t \geq 0}$ and $\left\{1 / P_{t}\right\}_{t \geq 0}$ grow at the same rate as technology $\left\{A_{t}\right\}_{t \geq 0}$ which evolves as in eq. (17).

\subsection{Firm size distribution}

Let $m_{g l}[n]$ be the mass of good type, large firms supplying $n$ product lines. By equating the inflow and outflow I obtain the following system of difference equations:

$$
\begin{array}{ll}
n>2: & m_{g l}[n] n\left(\delta+\gamma_{l}\right)=m_{g l}[n+1](n+1) \delta+m_{g l}[n-1](n-1) \gamma_{l} \\
n=2: & m_{g l}[2] 2\left(\delta+\gamma_{l}\right)=m_{g l}[3] 3 \delta+m_{g l}[1] 1 \gamma_{l}+\gamma_{g s}^{s} \zeta_{g s}^{s}+\gamma_{g s}^{l} \zeta_{g s}^{l} \\
n=1: & m_{g l}[1] 1\left(\delta+\gamma_{l}\right)=m_{g l}[2] 2 \delta
\end{array}
$$

where $\gamma_{l} \equiv \sum_{f \in\{s, l\}} \zeta_{g l}^{f} \gamma_{g l}^{f} / \sum_{f \in\{s, l\}} \zeta_{g l}^{f}$ is the innovation rate chosen by large firms across product lines, on average. By inspection it can be verified that $m_{g l}[n]=a \theta_{l}^{n-2} / n$ solves the first equation with $\theta_{l} \equiv \gamma_{l} / \delta$ and $a$ equal to some constant. Next I use the first and third expressions to write $m_{g l}[3]$ and $m_{g l}[1]$ in terms of $m_{g l}[2]$, substitute out for $m_{g l}[3]$ and $m_{g l}[1]$ in the second expression, solve for $a$ and obtain the closed form solution:

$$
\begin{aligned}
m_{g l}[n] & = \begin{cases}\frac{\theta_{s}\left(1+\theta_{l}\right) \theta_{l}^{n-2}}{n}, & n \geq 2 \\
\theta_{s}, & n=1\end{cases} \\
\theta_{s} & \equiv \zeta_{g s}^{s} \frac{\gamma_{g s}^{s}}{\delta}+\zeta_{g s}^{l} \frac{\gamma_{g s}^{l}}{\delta} \\
\theta_{l} & \equiv \frac{\gamma_{l}}{\delta}
\end{aligned}
$$


The overall firm size distribution $\left.\mu_{[} n\right]$ is then equal to:

$$
\begin{gathered}
\mu[n]= \begin{cases}\frac{\theta_{s}\left(1+\theta_{l}\right)}{\Theta} \frac{\theta_{l}^{n-2}}{n}, & n \geq 2 \\
\frac{\theta_{\eta}}{\Theta}, & n=1\end{cases} \\
\Theta \equiv \theta_{\eta}+\theta_{s}\left(1+\theta_{l}\right) \frac{\ln \frac{1}{1-\theta_{l}}-\theta_{l}}{\theta_{l}^{2}}
\end{gathered}
$$

where $\Theta$ is the total mass of firms in the economy, $\theta_{\eta} \equiv \eta / \delta$ and I made use of $\theta_{\eta}=\zeta_{s}+\theta_{s}$ which follows from adding eq. (15a) to eq. (15b) and dividing through by $\delta .{ }^{4}$ The firm size distribution is entirely determined by three quantities: $\theta_{\eta} \equiv \eta / \delta, \theta_{s} \equiv \zeta_{g s}^{s} \gamma_{g s}^{s} / \delta+\zeta_{g s}^{l} \gamma_{g s}^{l} / \delta$ and $\theta_{l} \equiv \gamma_{l} / \delta$. Such quantities reflect the tension between the sullying effect of entry, $\theta_{\eta}$, and the cleansing effect of the innovation effort exerted by incumbents, whether small or large, $\theta_{s}$ and $\theta_{l}$. The intensity of the creative destruction process, $\delta$, is irrelevant for the steady state degree of selection in the economy; what matters is instead how $\delta$ brakes down into $\eta$ on one hand and $\gamma_{g s}^{s}, \gamma_{g s}^{l}, \gamma_{l}$ on the other. Tax evasion lowers $\theta_{s}$ relative to $\theta_{\eta}$ - both due to the regularization cost and to unfair competition compressing the size distribution to the left. Furthermore it reduces $\theta_{l}$ relative to $\theta_{\eta}$ because of unfair competition.

\section{$3 \quad$ Identification and calibration strategy}

I assume that the monitoring probability function and innovation cost function have the power form:

$$
\begin{aligned}
& \operatorname{Pr}(\lambda x, n)=a_{n}(\lambda x)^{a} \\
& a_{n}= \begin{cases}a_{s} & \text { if } n=1 \\
a_{l} & \text { if } n>1\end{cases}
\end{aligned}
$$

with $a_{s} \leq a_{l}$ and $a \geq 1$, and:

$$
\iota(\gamma \mid w)=\left(1+\tau_{l}\right) w \iota_{0} \gamma^{1+\iota_{1}}
$$

with $\iota_{0}>0$ and $\iota_{1}>0$.

In appendix B I characterize the model solution in the case with no tax evasion $a_{s} \rightarrow \infty$ and show that under the assumption that $\iota$ is a power function and

\footnotetext{
${ }^{4}$ The total mass of firms is computed noting that:

$$
\begin{aligned}
\sum_{n=2}^{\infty} \frac{\theta_{l}^{n-2}}{n} & =\frac{1}{\theta_{l}^{2}}\left[-\theta_{l}+\sum_{n=1}^{\infty} \frac{\theta_{l}^{n}}{n}\right]=\frac{1}{\theta_{l}^{2}}\left[-\theta_{l}+\sum_{n=1}^{\infty} \int_{0}^{\theta_{l}} x^{n-1} d x\right] \\
& =\frac{1}{\theta_{l}^{2}}\left[-\theta_{l}+\int_{0}^{\theta_{l}} \sum_{n=1}^{\infty} x^{n-1} d x\right]=\frac{1}{\theta_{l}^{2}}\left[\ln \frac{1}{1-\theta_{l}}-\theta_{l}\right]
\end{aligned}
$$
}


given that the risk free rate $r$ is known, the model is identified only up to one of the three parameters $\left\{m, \iota_{0}, \iota_{1}\right\}$, if no information on innovation spending is available:

Proposition 2. Assume that $\iota(\cdot)$ is as in (21) and that there is no tax evasion (i.e. $a_{s} \rightarrow \infty$, if $\operatorname{Pr}$ is as in eq. 20) then:

$i$. there is one and only one balance growth path as defined in Definition 1;

ii. if the risk free rate can be observed, then the model is identified only up to one of the three parameters $\left\{m, \iota_{0}, \iota_{1}\right\}$, if no data on innovation spending is available.

Proof. (i.) See appendix B. (ii.) In appendix B I show that the equilibrium conditions can be rewritten as $\eta=\xi_{0}\left(m, \phi, \iota_{1}\right) \gamma, \delta=\xi_{1}\left(\phi, \xi_{0}\right) \gamma, \zeta_{g}=\xi_{2}\left(\phi, \xi_{0}, \xi_{1}\right)$ and $\gamma=\xi_{3}\left(\iota_{0}^{w}, \iota_{1}, q, \xi_{1}\right)$, where $\iota_{0}^{w} \equiv w \iota_{0}$, and that the aggregate growth rate is $\left(\xi_{0}+\xi_{2}\right) \gamma \ln q$. Then, given $\left\{\phi, \xi_{0}, q\right\}$, firm demographics, their evolution and the aggregate growth rate are fully determined. This provides four condition for five unknowns leaving one of the three parameters $\left\{m, \iota_{0}^{w}, \iota_{1}\right\}$ undetermined. Then, for example, given knowledge of $\iota_{1}$ I can invert $\xi_{0}$ and $\xi_{3}$ (which are invertible) and recover $m$ and $\iota_{0}^{w}$ respectively. As for $L$, note that any $w$ can be rationalized by picking the appropriate level of $L$ and $w$ determines the number of labor units used in the innovation process, given a value for $\iota(\cdot)$, or equivalently $\gamma$. Thus $w$ is one-to-one with the relative size of a type $g$ vs. a type $b$ firm.

Instead, with tax evasion and different degrees of tax enforcement across firms (i.e. $a_{s}$ finite, $a_{s}<a_{l}$ and $\zeta_{l}>0$ ) the model is fully identified, because at least two (and up to four) realizations of the innovation intensity choice are observed, for example $\gamma_{g s}^{l}=\iota^{\prime-1}\left(\cdot \mid \iota_{0}, \iota_{1}\right)$ and $\gamma_{g l}^{l}=\iota^{\prime-1}\left(\cdot \mid \iota_{0}, \iota_{1}\right)^{5}$. Then $\iota_{1}$ can be identified in theory by comparing the growth rate of small and large firms, for instance. In practice, small firms tend to be younger and younger firms tend to grow faster, possibly for reasons other than innovation. A possibility that I do not explore here is to compare the growth rate of small and large firms conditional on age. Instead I tune this parameter based on values found in the literature, as discussed below, and evaluate the robustness of counterfactuals to changes in $\iota_{1}$.

In appendix B I provide a formal argument and describe a practical strategy for calibrating the model without tax evasion, given $\iota_{1}$. The target statistics are reported in table 1 . In short, to the extent that incumbent firms invest in innovation, the exit probability declines with age; the entry rate and a point on the hazard curve provide information on $\eta$ and $\delta$ - or, analogously, two points on the hazard curve, since in steady state the entry rate equals the exit rate and a particular hazard function maps only into one exit rate. The relationship between average firm size and age is indicative of the magnitude of $\gamma$, given $\delta$ and $\phi$ - these three quantities fully describing the evolution of an incumbent firm in terms of the number of market niches. Finally, any aggregate growth rate can

\footnotetext{
${ }^{5}$ In the case of potential entrants one only observes $m \gamma_{0}$ and not $\gamma_{0}$ directly.
} 
always be rationalized by picking an appropriate level for $q$ - see eq. (17). As for the model with tax evasion, I set $a=1$ in (20) and then pick $a_{s}$ and $a_{l}$ to replicate the incidence of tax evasion in the economy.

Regarding $\iota_{1}$, Acemoglu et al. (2013) estimate a model similar to Lentz and Mortensen (2008) on a sample of innovative firms using R\&D and patent data and find $\iota_{1}=1.75$. They also discuss various micro-econometric estimates which are obtained either by examining the relationship between R\&D expenditure and patents or the response of $\mathrm{R} \& \mathrm{D}$ expenditure to changes in taxes and subsidies. The empirical results in these studies point to a value for $\iota_{1}$ in the range $[0.7,2.3]$. Instead Lentz and Mortensen (2008) structurally estimate their model with three types on a panel of Danish firms with at least 20 employees using data on wages and value added and find $\iota_{1}=3.73$. I set $\iota_{1}=2$ and then in the robustness section consider how results are affected by changing the value of this parameter.

I compute firm demographics using social security data covering the universe of Italian employer businesses between 1990 and 2013. The data contains information on the number of employees and the wagebill, sector and province, along with entry and exit dates. ${ }^{6}$ I aggregate observations at the firm level, using the fiscal code as the definition for what constitutes a firm. I restrict attention to the non-agricultural business sector (NACE R1.1 sector C to K) and focus on the years between 1995 and 2006, i.e. after the recovery that followed the 1992 recession and before the onset of the financial crisis. Descriptive statistics are reported in table 5 of appendix $\mathrm{C}$.

I consider the 5 cohorts born between 1995 and 1999 and follow them through to 2006. The left panel of figure 3 displays the exit probability derived from life table estimates of the survival functions for each of the 5 cohorts along with the growth rate of average size by age - right panel. I average across cohorts and take as targets for the calibration the average hazard between age 6 and 8 and between age 9 and 11 and the average growth rate between age 9 and 11. The reason for disregarding earlier years is that other mechanisms, such as learning or time-to-build, might be more important in explaining the exit rate or firm growth in the first few years of a firm life-cycle - Jovanovic (1982) and Ericson and Pakes (1995). Indeed, average firm size doubles within one year of entering (not reported).

Regarding the level of tax evasion, I assume that large firms do not evade taxes $\left(a_{l} \rightarrow \infty\right)$ and target the fraction of underground full time equivalent employees estimated by the National Statistical Institute for the period under consideration in Italy - Istat (2011). The assumption that large firms do not evade is a simplification which is dictated by the lack of empirical evidence regarding the propensity to evade taxes across different size classes. In facts, the Ital-

\footnotetext{
${ }^{6}$ The data covers all legal entities making social security contributions for at least one employee worker during at least a month in a given year. Entry (Exit) dates are defined as the earliest entry (latest exit) date of the legal entities sharing the same fiscal code. With regard to exit I limit the attention to exits which are flagged in the same year when the exit is supposed to occur. See Adamopoulou, Bobbio, De Philippis, and Giorgi (2016a) for a more thorough description of the data.
} 
Figure 1: Firm dynamics, cohorts 1995-1999 (INPS)

Hazard of exit

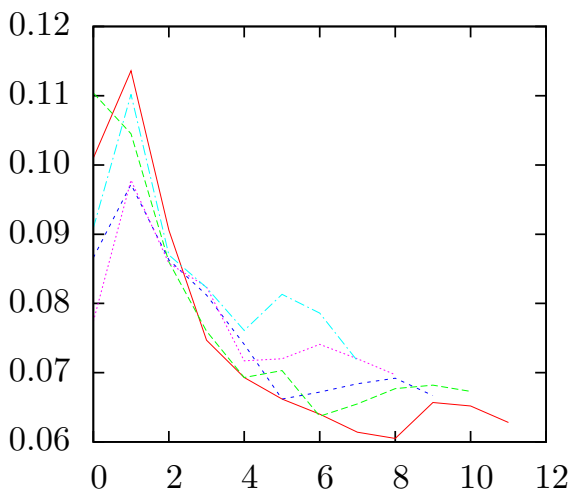

Size by age (avg. gr.)

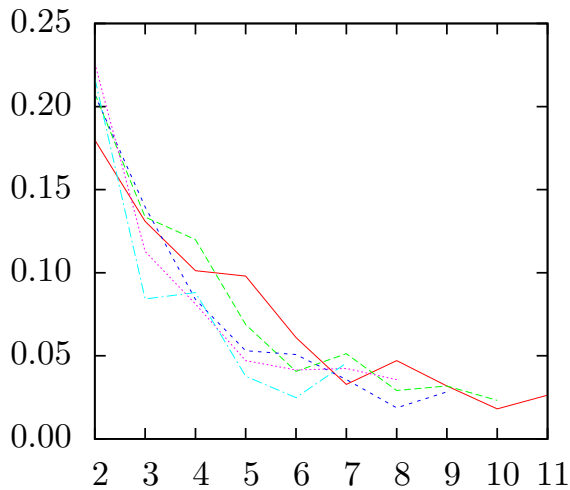

Exit probability and growth rate of average size by age, private business sector, cohorts 19951999. Source: INPS data

ian Revenue Agency does report recovering unpaid taxes from small as well from large firms - Ministero dell'Economia e delle Finanze (2014). However, as discussed in the introduction firms with a turnover above 100mln euros (approximately 300 employees) are twenty times more likely to be monitored than small and individual firms $-39 \%$ and $2 \%$ respectively, Agenzia delle Entrate (2015). Furthermore the official estimate on the fraction of unreported turnover by individual firms between 2007 and 2008 is 34.7\% - Ministero dell'Economia e delle Finanze (2014). Finally, the number I use as a target for the incidence of tax evasion is the lowest among available estimates - see the discussion in the introduction - and what matters is the difference between how much small and large firm evade. In the robustness section I also consider the case where large firms evade same taxes and the overall level of tax evasion is higher than considered here.

As a measure of economic growth I consider chained value added at basic prices per hour worked in the private business sector (Eurostat national accounts). Finally, I set tax rates on value added, profits, turnover and the penalty parameter $\left\{\tau_{v a}, \tau_{p f}, \tau_{t o}, \nu\right\}$ based on statutory rates. For the labor wedge $\tau_{l}$ I consider the difference between the labor cost and take home income pay from the OECD tax database - OECD (2016) - and take averages for the years 2000-2006, 2000 being the first year covered by that data. This approach reflects the view that the labor cost in the underground sector is cheaper because it is not burdened by income taxes and social security contributions; also numbers are consistent with the findings underlying the correction of the Italian national accounts implemented by Istat to account for the shadow economy, Istat (2014). 
Table 1: Calibration: targets and resulting model parameters

\begin{tabular}{|c|c|c|c|c|c|c|c|}
\hline \multicolumn{8}{|c|}{ Target statistics } \\
\hline $\begin{array}{l}\text { hazard }^{a} \\
\text { age } 6-8\end{array}$ & $\begin{array}{l}\operatorname{hazard}^{a} \\
\text { age } 9-11\end{array}$ & $\begin{array}{l}\text { size } \times \text { age } \\
\text { gr.th } 9-11\end{array}$ & $\begin{array}{l}\text { VA/hour } \\
\text { growth }^{b}\end{array}$ & $\begin{array}{c}\text { shadow } \\
\text { FTE }^{c}\end{array}$ & & & \\
\hline .06804 & .06533 & .02643 & .00921 & 0.12 & & & \\
\hline \multicolumn{8}{|c|}{ Parameters set ex-ante } \\
\hline$\nu^{d}$ & $\tau_{v a}^{d}$ & $\tau_{p f}^{d}$ & $\tau_{t o}{ }^{d}$ & $\tau_{l}^{e}$ & $r$ & $\iota_{1}$ & $a$ \\
\hline 0.30 & 0.20 & 0.275 & 0.039 & 0.86 & 0.05 & 2.0 & 1.0 \\
\hline \multicolumn{8}{|c|}{ Parameters calibrated based on target statistics } \\
\hline$m$ & $\phi$ & $q$ & $\iota_{0}$ & $a_{s}$ & & & \\
\hline 0.668 & 0.467 & 1.175 & 60.95 & 2.706 & & & \\
\hline
\end{tabular}

$\overline{{ }^{a} \text { Averages over age intervals } 6 \text { to } 8 \text { and } 9 \text { to } 11 \text {, see note to figure } 3{ }^{b} \text { Chain linked Value }}$ added at basic prices per hour worked, average growth rate over the period 1995-2006, source Eurostat. ${ }^{c}$ Fraction of FTE working underground approximate number of the period 19952006, Istat (2011). All quantities refer to the private business sector. ${ }^{d}$ Statutory rates. ${ }^{e}$ Labor cost/take home pay - 1, average over the period 2000-2006, OECD (2016).

\section{Results}

Any wage can be rationalized by picking the appropriate labor supply level, $L$. Therefore I set $w=1$ and look for the combination of model parameters $\left\{m, \phi, q, \iota_{0}, a_{s}\right\}$ minimizing the distance with the the data. The target statistics and the resulting model parameters are reported in table 1 . The calibrated model perfectly matches the targets.

Table 2 displays equilibrium values for some variables along with relevant statistics computed on the data generated by the model. The fraction of firms that are able to produce innovation is $\phi=46.7 \%$ at entry. By investing in innovation these firms tend to displace less productive one, increasing their output share by 28 percentage points to $74.7 \%$ in equilibrium. However the innovation rate chosen by small type $g$ firm is roughly half that of large type $g$ firms hinting to an imperfectly functioning selection mechanism, as further discussed below. Revenues represent $49.7 \%$ of output, which is higher than the value reported for example in the OECD tax database for the period 1995-2006, 40.1\%. Also, the model does not account other sources of government revenues, such as property taxes or excise duties. On the other hand the latter statistic refers to the overall economy, while the number displayed in table 2 is for the private sector only and, for example, value added taxes are not levied on public services such as publicly provided education or healthcare; also, rates can be lower for certain items, such as food, books, medicines, or zero for example in the case of financial services. The investment in innovation activity represents $2.6 \%$ of GDP. Private sector R\&D expenditure in Italy is approximately $0.7 \%$ of GDP; the service sector contribution to $\mathrm{R} \& \mathrm{D}$ expenditure is negligible and industry represent approximately $1 / 4$ of GDP. In addition, innovation investment in the model has a broader interpretation and may encompass investments in equipment and skills 
improving the productivity of the firm, both in terms of production efficiency or product quality. All in all, I interpret the model outcome of a $2.6 \%$ innovation investment share of GDP as a reasonable number, perhaps on the low side. As shown below, reducing the value of $\iota_{1}$ - towards the quadratic case as in Acemoglu et al. (2013) - increases this figure along with the estimated cost of tax evasion, in terms of a lower long-run aggregate growth rate. The entry rate (or equivalently the exit rate) is $5.8 \%$ accounting for $2 / 3$ of the corresponding figure reported in official statistics, approximately $8.5 \%$. As remarked above the calibration aims at capturing the component of firm dynamics fueled by innovation and it abstracts from other mechanisms such as imperfect information which are likely to play an important role especially in the first few years of a firm life-cycle, or from supply and demand shocks. $10.6 \%$ of firms that are born during a given year $t$ exits by the end of year $t+1$. Average employment size - including underground employment - of surviving businesses grows by $1.6 \%$ a year between age 9 and $11 . .^{7}$ Average firm size in the economy in terms of product lines, or equivalently turnover or value added, is 1.62 .

\subsection{Policy experiment: enforcing taxes}

I now consider the effect of curbing tax evasion. Results are reported in the second row of table 2 . As $a_{s}$ grows to infinity tax evasion decreases. In the limit the long run growth rate increases by 0.2 percentage points from 0.92 to $1.13 \%$. Such a change comes about through several channels. As $v_{g s}^{f} \rightarrow v_{g l}^{f}$ in eq. (12b) the cost of regularization disappears and small innovative firms increase their innovation effort to the level of that of large firms, $\gamma_{g s} \rightarrow \gamma_{g l}$. Because unfair competition also fades, $v_{g d}^{s} \rightarrow v_{g d}^{l}$ in eqs. (12b) and (12c), both small and large innovative firms increase their innovation expenditure further. The aggregate destruction rate $(\delta)$ increases despite the weakening entry flow $(\eta)$ which is due to the decline in the value of being a small firm, when the scope for tax evasion vanishes - all firms are small when they enter the market. The increased innovation expenditure by innovative firms and the drop in the entry rate both contribute to stricter selection. Small, less productive firms are pushed out of the market and the share of value added produced by innovative firms increases from 74.7 to $82.4 \%$. Thus, the aggregate growth rate increases both along the intensive and along the extensive margin. The negative contribution from the decline of entry is mitigated by the fact that only a fraction $\phi=0.47$ of entries is associated with an improvement in productivity, eq. (17). Finally, note that the general equilibrium effect via the labor market is also positive. Since more productive firms require less labor for production, the compositional shift towards more productive firms frees up resources, the wage declines lowering the cost of innovation and part of the labor is reabsorbed into innovative activities whose share rises from 3.0 to $4.1 \%$ of employment (not reported).

As for firm demographics, a higher degree of tax enforcement is also associated

\footnotetext{
${ }^{7}$ This is the growth rate of actual size in terms of the total number of employees, including those underground, as apposed to the figure reported in table 1 which refers to employees for which the firm pays social security contributions.
} 


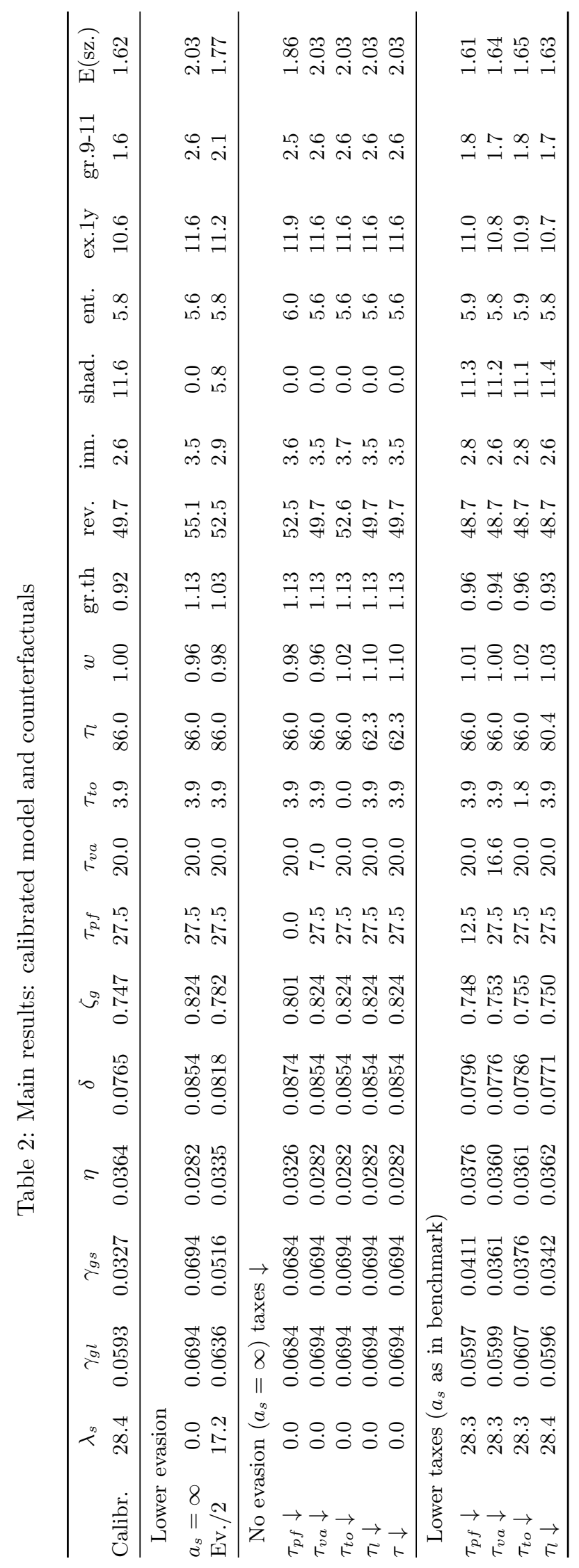


with a higher early exit probability (the probability for a firm born in $t$ of not surviving to the end of $t+1$ increases by 1 percentage point) and with a marked increase in the rate of firm expansion (average firm size rises with each year of age by 2.6 as opposed to $1.6 \%$, between age 9 and 11). As a result mean firm size increases by $24.8 \%$.

The third row displays results for the case where $a_{s}$ is increased so to halve the fraction of underground employment in the economy. In this case the growth rate increases by 0.1 percentage point to 1.03 . With a higher level of tax enforcement, the fraction of market niches supplied by large firms grows from $59.1 \%$ to $66.5 \%$ (not reported). Thus not only selection contributes to growth by increasing the share of economic activity commanded by firms engaging in innovation, but it also decreases the scope for unfair competition, further sustaining innovative activity and long-run growth, $v_{l} \equiv \zeta_{s} v_{g l}^{s}+\left(1-\zeta_{s}\right) v_{g l}^{l}$ in eqs. (12b) and (12c).

\subsection{Policy experiment: lowering taxes}

With no tax evasion the proceeds collected by the government increase by 5.4 percentage points. In the row from 5 to 9 of table 2 I report results for the case where such resources are used to lower taxes. The effect on aggregate growth is nil. In facts, the analysis in appendix B indicates that value added taxes and the labor wedge have no effect on aggregate growth, while a cut in corporate or turnover taxes have an ambiguous effect, when labor is the only input entering the innovation process and there is no tax evasion.

Results are different when there is tax evasion. As displayed in the bottom part of table 2, a cut in statutory tax rates such to reduce government revenues by 1 percentage point has a significant impact on the long run rate of economic expansion which increases by approximately 4 basis points in the case of a cut in corporate and turnover taxes. This is essentially because cutting taxes reduces the benefits from tax evasion and thus both, the cost of regularization and the extent of unfair competition, in a similar manner as enforcing taxes.

\section{Robustness}

\subsection{Innovation via the final good}

Suppose innovation requires investing into the final good instead of labor and suppose that the amount of the final good that a firm must purchase at a plant to generate a given arrival rate of innovation grows with the level of technology attained by the economy up to that point:

$$
\iota(\gamma \mid P, A)=P A \iota_{0} \gamma^{1+\iota_{1}}
$$




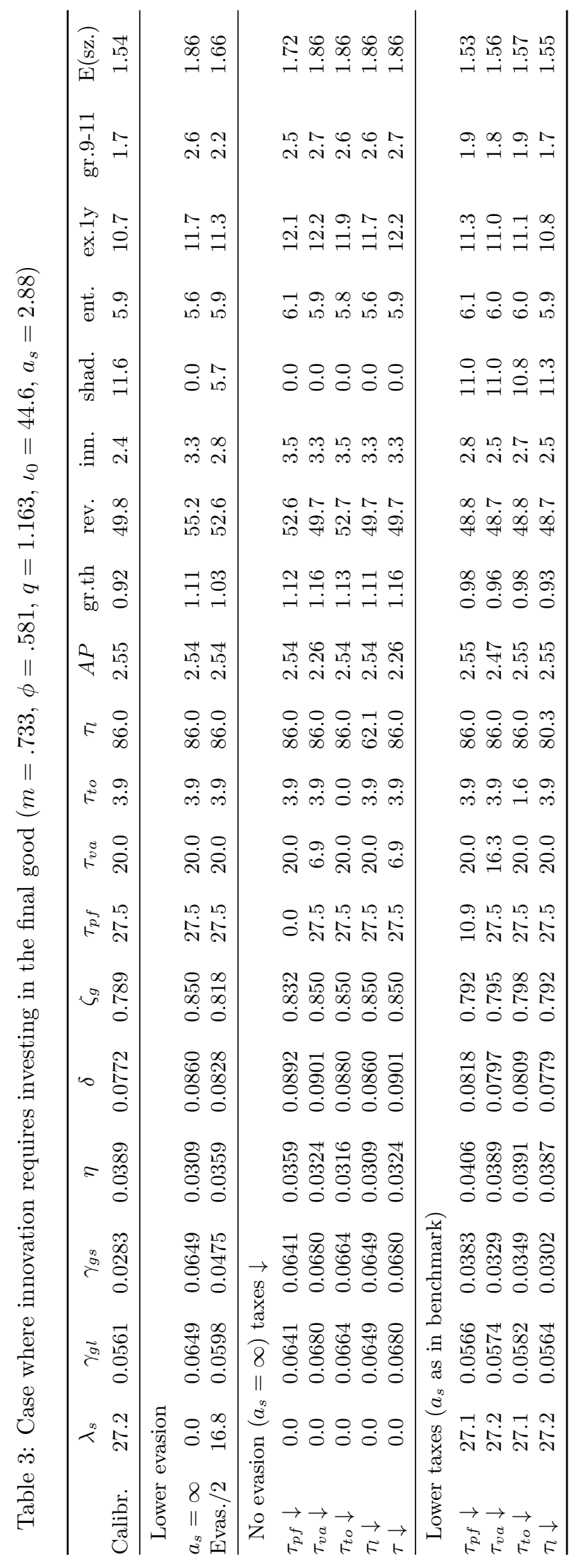


The model is exactly as above except that the labor market clearing condition simplifies to:

$$
L=\sum_{z \in\{b, g\}} \sum_{f \in\{s, l\}} \zeta_{z}^{f} \frac{1}{p_{z}^{f}}
$$

and given the normalization $P_{t} Y_{t} /\left(1+\tau_{v a}\right)=1$ and eq. (5):

$$
\ln (A P)=\int_{0}^{1} \ln \left[\left(1+\tau_{v a}\right) p_{i t}\right] d i=\sum_{z \in\{b, g\}} \sum_{f \in\{s, l\}} \zeta_{z}^{f} \ln \left[\left(1+\tau_{v a}\right) p_{z}^{f}\right]
$$

In table 3 I report the results for this case. The table contains the same information as table 2 - except that it displays the (constant) product $A P$ instead of $w$, which does not play any role here, as apparent from the labor market clearing condition, eq. (23). The effect of enforcing taxes is essentially the same, both regarding the long-run growth rate (which increases from 0.92 to $1.11 \%$ ) and firm dynamics (the entry rate slightly declines, the exit probability within one year of entry increases by 1 percentage point, average employment grows with age at 2.6 vs. $1.7 \%$, mean firm size increases by $20.7 \%$ ). However the impact of lowering taxes is higher. Under eq. (23), eq. (41a) in appendix B implies that the labor wedge has no effect on growth, while corporate, turnover and value added taxes lower the long-run growth rate, when there is no tax evasion. Table 3 shows that using all the extra proceeds from tax enforcement to reduce the value added tax rate to $6.9 \%$ would boost aggregate growth by another 5 basis points to $1.16 \%$. A similar result would also be obtained by reducing turnover taxes as the elasticity is approximately the same. Value added taxes have an effect on the long run growth rate when the final good is necessary for the innovation process because they make it more expensive. The impact of reducing taxes at the calibrated value of the tax enforcement parameter is also stronger: a reduction in corporate or turnover taxes resulting in government revenues 1 percentage point lower boost aggregate growth by 6 basis points (by 4 and 1 in the case of an equivalent reduction of value added taxes and the labor wedge respectively). Similarly to the case where innovation requires labor, the policy maker can boost growth either by enforcing taxes or by reducing statutory tax rates; both approaches lower the cost advantage of evading taxes, leveling the field out in the Stackelberg game between the leader and the follower.

\subsection{Other robustness checks}

Finally I test the robustness of the results with respect to changes in the elasticity of the innovation cost function, $1+\iota_{1}$, and with respect to different target statistics. In table 4 I report results for the cases where the model is calibrated on the same targets as in table 1 but $\iota_{1}=1.5$ or $\iota_{1}=3.5$. The other calibrated parameters are similar to those obtained when $\iota_{1}=2$ along with equilibrium outcomes. As mentioned above and implicit in the identification argument, spending on innovation as a fraction of GDP varies significantly, decreasing from 3.0 to $1.6 \%$ when $\iota_{1}$ is increased from 1.5 to 3.5. The impact on the longrun growth rate of shutting down tax evasion also depends on the value of $\iota_{1}$ 


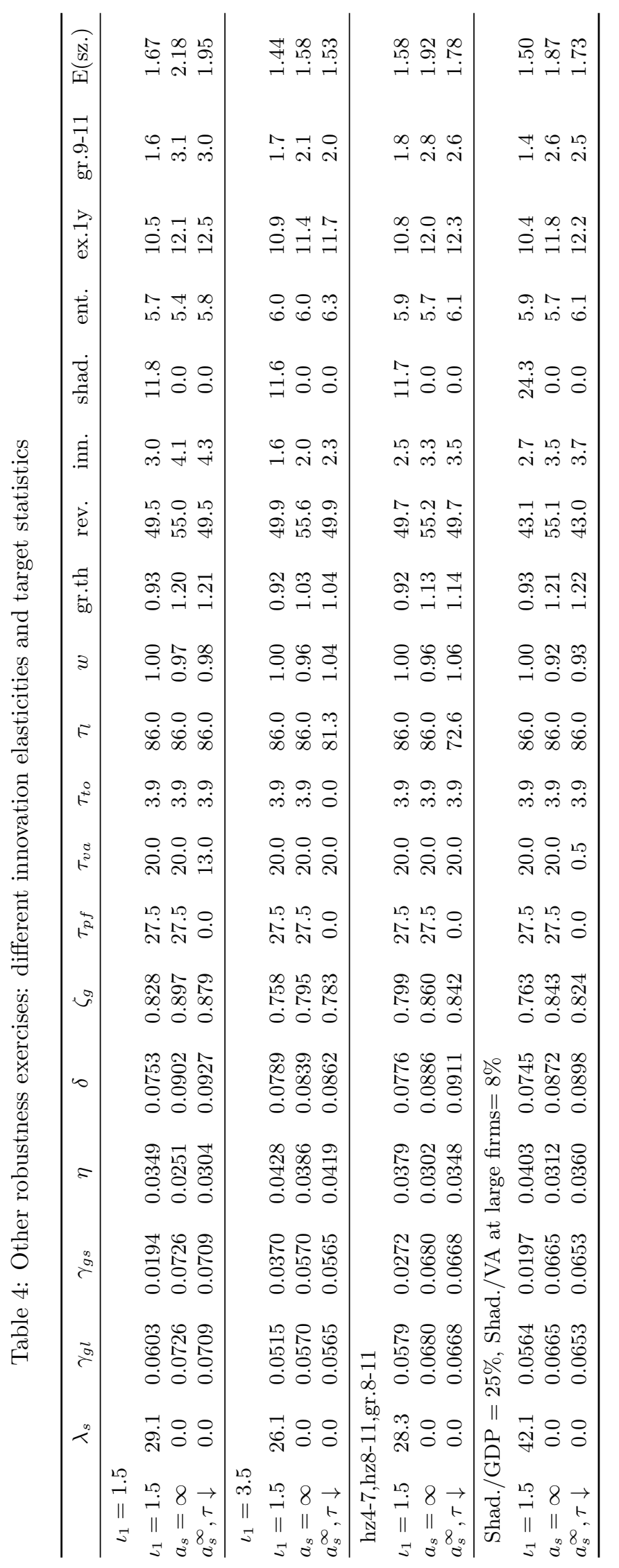


and it is stronger the lower the value of this parameter. When lowering $\iota_{1}$ from 2 to 1.5 the impact on the long-run growth rate increases from 20 to 30 basis points. When raising it to 3.5 it is lower but remains economically significant at 10 basis points. A similar pattern holds for firm demographic statistics.

I then check the robustness of results with respect to changes in the target statistics used for the calibration. In the main calibration exercise I ignore the early years of a firm life-cycle, because other factors may play a more important role than innovation in driving firm demographics, and consider the hazard function after age 6 and the employment growth rate after age 9 . Here I vary the age range and consider the average exit probability age $4-7=.0709$, the average exit probability age $8-11=.0657$ and the growth rate of average size age $8-11=.0280$. Results are reported in the third part of table 4 and are broadly unaffected relative to the benchmark. The long-run growth rate in the case with no tax evasion is 1.14. Finally in the last part of the table I display results for the case where the model is calibrated based on Schneider and Williams (2013)'s estimate of the size of the shadow economy as a percentage of GDP which I set at $25 \%$. If large firms are not allowed to evade taxes the cost advantage associated with tax evasion is high enough that there is no innovation by incumbent and the model cannot replicate the data. I then allow large firms to evade taxes and set a target of $8 \%$ for the fraction of output they conceal underground. Under this calibration the effect of shutting down tax evasion is stronger and the long-run growth rate rises to $1.21 \%$ when shutting down tax evasion.

\section{Conclusions}

I showed that in a Schumpeterian model of growth with heterogeneous firms tax evasion reduces the long-run growth rate, if smaller firms are less likely to be monitored by the tax enforcement authority. Under these circumstances small firms spend less on innovation and remain small so as to stay under the "radar" - or, formally, not to incur the (shadow) cost of tax regularization associated with growth. The cost advantage enjoyed by firms with a higher scope for tax evasion results in unfair competition, lowering the incentives to innovate for all firms. Both these channels depress the innovative activity of incumbent firms in the economy. As a result there is less selection in equilibrium and the economy is populated by higher fraction of small, less productive and less innovative firms than it would be in the absence of tax evasion, further reducing the aggregate growth rate along the extensive margin. In addition a larger fraction of small firms with a higher scope for tax evasion increases the degree of unfair competition, potentially triggering a vicious cycle where the growth process brakes down and incumbent firms stop innovating.

Counterfactual exercises based on a calibrated version of the model suggest that enforcing taxes would have increased the long-run growth rate from 0.9 to $1.1 \%$ in Italy, with reference to the period between 1995 and 2006. Lowering taxes would have also increased growth, because it would have reduced the cost advantage from tax evasion, which is substantial when both the shadow 
economy is large and statutory rates are high. Enforcing taxes also would have affected firm dynamics: the entry rate would have been lower in equilibrium and the exit probability higher in the first few years following entry, while the employment growth rate of surviving firms would have increased, resulting in a higher average firm size. 


\section{References}

D. Acemoglu, U. Akcigit, N. Bloom, and W.R. Kerr. Innovation, reallocation and growth. 2013.

E. Adamopoulou, E. Bobbio, M. De Philippis, and F. Giorgi. Allocative efficiency and aggregate wage dynamics in italy, 1990-2013. Banca d'Italia, Quaderni di Economia e Finanza, forthcoming, 2016a.

Agenzia delle Entrate. Risultati 2015 e strategie 2016, 2015.

P. Aghion and P. Howitt. A model of growth through creative destruction. Econometrica, 60(2):323-351, 1992.

P. Aghion, U. Akcigit, J. Cagé, and W.R. Kerr. Taxation, corruption, and growth. European Economic Review, 2016.

U. Akcigit, H. Alp, and M. Peters. Lack of selection and limits to delegation: firm dynamics in developing countries. University of Chicago, mimeo, 2016.

G. Ardizzi, C. Petraglia, M. Piacenza, and G. Turati. Measuring the underground economy with the currency demand approach: a reinterpretation of the methodology, with an application to italy. Review of Income and Wealth, 60(4):747-772, 2014.

E. Bartelsman, J. Haltiwanger, and S. Scarpetta. Cross country differences in productivity: The role of allocation and selection. American Economic Review, forthcoming, 2012.

F.J. Buera, J.P. Kaboski, and Y. Shin. Finance and development: A tale of two sectors. The American Economic Review, 101(5):1964-2002, 2011.

L. Cannari and G. d'Alessio. Le opinioni degli italiani sull'evasione fiscale. Temi di Discussione, 618, 2007.

C. Criscuolo, P.N. Gal, and C. Menon. The dynamics of employment growth. 2014.

R. Ericson and A. Pakes. Markov-perfect industry dynamics: A framework for empirical work. The Review of Economic Studies, 62(1):53-82, 1995.

G.M. Grossman and E. Helpman. Innovation and growth in the global economy. MIT press, 1991.

N. Guner, G. Ventura, and Y. Xu. Macroeconomic implications of sizedependent policies. Review of Economic Dynamics, 11(4):721-744, 2008.

H.A. Hopenhayn. On the measure of distortions. NBER, 2014.

C.T. Hsieh and P.J. Klenow. Misallocation and manufacturing tfp in china and india. The Quarterly Journal of Economics, 124(4):1403-1448, 2009. 
Istat. La misura delloccupazione non regolare nelle stime di contabilità nazionale, 2011.

Istat. La revisione della stima dei redditi da lavoro dipendente. 2014.

Istat. L'economia non osservata nei conti nazionali, 2015.

B. Jovanovic. Selection and the evolution of industry. Econometrica: Journal of the Econometric Society, pages 649-670, 1982.

T.J. Klette and S. Kortum. Innovating firms and aggregate innovation. Journal of Political Economy, 112(5):986-1018, 2004.

R. Lentz and D.T. Mortensen. An Empirical Model of Growth Through Product Innovation. Econometrica, 76(6):1317-1373, 2008.

R. Lentz and D.T. Mortensen. Optimal growth through product innovation. Review of Economic Dynamics, 2015.

F. Manaresi. Net employment growth by firm size and age in italy. Banca d'Italia, Questioni di Economia e Finanza, 298, 2015.

V. Midrigan and D.Y. Xu. Finance and misallocation: Evidence from plant-level data. American Economic Review, 104(2):422-458, 2014.

Ministero dell'Economia e delle Finanze. Nota di aggiornamento del documento di economia e finanza 2015, rapporto sui risultati conseguiti in materia di misure di contrasto dell'evasione fiscale, 2014.

B. Moll. Productivity losses from financial frictions: can self-financing undo capital misallocation? The American Economic Review, 104(10):3186-3221, 2014.

OECD. Taxing wages 2016. 2016.

D. Restuccia and R. Rogerson. Policy distortions and aggregate productivity with heterogeneous establishments. Review of Economic Dynamics, 11(4): 707-720, 2008.

P.M. Romer. Endogenous technological change. Journal of Political Economy, 98(5), 1990.

F. Schneider and D.H. Enste. Shadow economies: Size, causes, and consequences. Journal of Economic Literature, 38:77-114, 2000.

F. Schneider and C.C. Williams. The shadow economy. Institute of Economic Affairs, London, 2013.

R. Torrini. Cross-country differences in self-employment rates: The role of institutions. Labour Economics, 12(5):661-683, 2005. 


\section{A A Stackelberg game: pricing, tax evasion and innovation effort choices}

A size $n$ firm supplying $x$ unit of output at price $p\left(1+\tau_{v a}\right)$, evading taxes on a fraction $\lambda$ of output, exerting innovation effort $\gamma$ and facing a value of innovation $v$, has an expected payoff equal to:

$$
\pi(p, x, \lambda, \gamma \mid n)+\gamma v
$$

where $\pi$ is the profit flow:

$$
\begin{aligned}
\pi(p, x, \lambda, \gamma \mid n)= & \left(1-\tau_{p f} \mathbb{1}_{\Pi_{c}^{\lambda, \gamma}>0}\right) \Pi_{c}^{\lambda, \gamma}(p, x)-(1-\lambda) \tau_{t o} p x+\lambda \Pi_{n c}(p, x) \\
& -(1+\nu) \operatorname{Pr}(\lambda x \mid n) \Upsilon(p, x, \lambda, \gamma)
\end{aligned}
$$

$\Upsilon$ is total amount of taxes unpaid by the firm and $\Pi_{c}^{\lambda, \gamma}(p)$ and $\Pi_{n c}(p)$ are the profit flows generated in the regular establishment (gross of turnover taxes) and in the shadow establishment respectively:

$$
\begin{aligned}
\Upsilon(p, x, \lambda, \gamma) & =\lambda\left(\tau_{v a} p x+\tau_{t o} p x+\tau_{l} w x\right)+\tau_{p r}\left[\mathbb{1}_{\Pi_{c}^{0, \gamma}>0} \Pi_{c}^{0, \gamma}(p, x)-\mathbb{1}_{\Pi_{c}^{\lambda, \gamma}>0} \Pi_{c}^{\lambda, \gamma}(p, x)\right] \\
\Pi_{c}^{\lambda, \gamma}(p, x) & =(1-\lambda) \Pi_{c}(p, x)-\iota(\gamma) \\
\Pi_{c}(p, x) & =p x-x \varsigma_{c} \\
\Pi_{n c}(p, x) & =\left(1+\tau_{v a}\right) p x-x \varsigma_{n c}
\end{aligned}
$$

Substituting for the demand function, $x=1 / p$, and using the fact that $\tau_{l} w=$ $\varsigma_{c}-\varsigma_{n c}$ when labor is the only input to production (or when there is no substitution between labor and capital) the profit flow can be rewritten as:

$$
\begin{aligned}
\pi(p, \lambda, \gamma \mid n)= & \left(1-\tau_{p f} \mathbb{1}_{\Pi_{c}^{\lambda, \gamma}>0}\right) \Pi_{c}^{\lambda, \gamma}(p)-(1-\lambda) \tau_{t o}+\lambda \Pi_{n c}(p) \\
& -(1+\nu) \operatorname{Pr}(\lambda / p \mid n) \Upsilon(p, \lambda, \gamma) \\
& +\gamma v \\
\Upsilon(p, \lambda, \gamma)= & \lambda\left[\tau_{t o}+\Pi_{n c}(p)-\Pi_{c}(p)\right]+\tau_{p r}\left[\mathbb{1}_{\Pi_{c}^{0, \gamma}>0} \Pi_{c}^{0, \gamma}(p)-\mathbb{1}_{\Pi_{c}^{\lambda, \gamma}>0} \Pi_{c}^{\lambda, \gamma}(p)\right] \\
\Pi_{c}^{\lambda, \gamma}(p)= & (1-\lambda) \Pi_{c}(p)-\iota(\gamma) \\
\Pi_{c}(p)= & 1-\frac{\varsigma_{c}}{p} \\
\Pi_{n c}(p)= & 1-\frac{\varsigma_{n c}}{p}+\tau_{v a}
\end{aligned}
$$

Equilibrium characterization: note that $\Pi_{c}^{\lambda, \gamma}(p)>0$ implies $\Pi_{c}^{0, \gamma}(p)>0$ therefore there are three possible cases:

A: $\Pi_{c}^{0, \gamma}(p)>0$ and $\Pi_{c}^{\lambda, \gamma}(p) \geq 0$

B: $\Pi_{c}^{0, \gamma}(p)>0$ and $\Pi_{c}^{\lambda, \gamma}(p)<0$ 
C: $\Pi_{c}^{0, \gamma}(p) \leq 0$ and $\Pi_{c}^{\lambda, \gamma}(p)<0$

Case A corresponds to the scenario where the firm reports positive profits in the formal establishment and case $\mathrm{C}$ to that where it would report negative profits even if no production where concealed from the tax authority. Case B is the intermediate case where the firm reports negative profits on formal production but were it compelled to report all production it would make positive profits after paying for labor and value added taxes and would have to pay profit taxes as well.

In cases $\mathrm{A}$ and $\mathrm{C}$ the expression for the profit flow simplifies to:

$$
\begin{aligned}
\pi(p, \lambda, \gamma \mid n) & =\left(1-\tau_{p f} \mathbb{1}_{\Pi_{c}^{\lambda, \gamma}>0}\right) \Pi_{c}^{\tilde{\lambda}, \gamma}(p)-(1-\widetilde{\lambda}) \tau_{t o}+\widetilde{\lambda} \Pi_{n c}(p) \\
\widetilde{\lambda} & \equiv \lambda[1-(1+\nu) \operatorname{Pr}(\lambda / p \mid n)]
\end{aligned}
$$

Where we suppress the arguments in $\widetilde{\lambda}(p, \lambda \mid n)$ to avoid clutter. Note that a firm would never choose $(p, \lambda)$ such that $(1+\nu) \operatorname{Pr}(\lambda / p \mid n)>1$, because in this case the expected cost of tax evasion would be higher than paying taxes outright:

$$
\begin{aligned}
\pi(p, \lambda, \gamma \mid n)= & \left(1-\tau_{p f} \mathbb{1}_{\Pi_{c}^{\lambda, \gamma}>0}\right) \Pi_{c}^{\lambda, \gamma}(p)-(1-\lambda) \tau_{t o}+\lambda \Pi_{n c}(p) \\
& -(1+\nu) \operatorname{Pr}(\lambda / p \mid n) \Upsilon(p, \lambda, \gamma) \\
& +\gamma v \\
< & \left(1-\tau_{p f} \mathbb{1}_{\Pi_{c}^{\lambda, \gamma}>0}\right) \Pi_{c}^{\lambda, \gamma}(p)-(1-\lambda) \tau_{t o}+\lambda \Pi_{n c}(p) \\
& -\Upsilon(p, \lambda, \gamma) \\
& +\gamma v \\
= & \pi(p, 0, \gamma \mid n)
\end{aligned}
$$

Therefore maximal value $\lambda$ can take is $\bar{\lambda}(p)=\min \left(1, p \operatorname{Pr}^{-1}(1 /(1+\nu))\right)$ and $\widetilde{\lambda} \in[0, \lambda] \subseteq[0,1]$. Also, note that $\widetilde{\lambda}$ is strictly concave in $\lambda$ provided that $\operatorname{Pr}$ is increasing and convex in $\lambda$.

In both cases, $\mathrm{A}$ and $\mathrm{C}$, the payoff function is strictly increasing in $p$ : it is a linear combination of two terms, both strictly increasing in $p$, where the weight shifts towards the larger of the two terms $-\Pi_{n c}>\Pi_{c}$ and $\partial \widetilde{\lambda} / \partial p>0-$ minus a positive term which declines as $p$ increases $-(1-\tilde{\lambda}) \tau_{t o}$.

As for case $\mathrm{B}$, the expression for the profit flow can be written as:

$$
\begin{aligned}
\pi(p, \lambda, \gamma \mid n)= & (1-\lambda)\left[\Pi_{c}(p)-\iota(\gamma)\right]+\lambda\left[\Pi_{n c}(p)-\iota(\gamma)\right]-(1-\lambda) \tau_{t o} \\
& -(1+\nu) \operatorname{Pr}(\lambda / p \mid n) \tau_{p f}\left[\Pi_{c}(p)-\iota(\gamma)\right] \\
& -(1+\nu) \operatorname{Pr}(\lambda / p \mid n) \lambda\left[\tau_{t o}+\tau_{v a}+\tau_{l} w / p\right]
\end{aligned}
$$

The term in the third line is strictly increasing in $p$. As for the terms in the first and second line note that the effect of an increase in $p$ via changes in $\Pi_{c}$ and $\Pi_{n c}$ is positive, since $\Pi_{n c}>\Pi_{c}, \forall p>0$ and $(1+\nu) \operatorname{Pr}(\lambda / p) \tau_{p f}<(1+\nu) \operatorname{Pr}(\lambda / p) \leq 1$. Also it has positive effect via changes in $\operatorname{Pr}$, because $\Pi_{c}(p)>\iota(\gamma)$ in case C by definition. Thus, the payoff function is increasing in $p$ in case B as well. Since 
the function is piecewise continuous, I conclude that it is globally increasing in $p$.

Because the payoff function is increasing in $p$, then for any admissible pair $(\lambda, \gamma)$ the leader optimally charges the maximal price such that the follower is priced out of the market. A customer buying the intermediate good is indifferent between paying a price $p$ for the vintage offered by the follower and paying $p q_{L}$ for the vintage offered by the leader where $q_{L} \geq 1$ measure the efficiency advantage of the latest vintage. Therefore, the solution to the game is characterized by the following conditions:

$$
\begin{gathered}
\text { follower stage: }\left\{\begin{array}{l}
\lambda_{F}=\arg \max \pi\left(p_{F}, \lambda, \gamma \mid n_{F}\right) \\
p_{L}: \max _{\lambda} \pi\left(p_{F}, \lambda, 0 \mid n_{F}\right)=0
\end{array}\right. \\
\text { leader stage: }\left(\lambda_{L}, \gamma_{L}\right)=\arg \max \pi\left(p_{F} q_{L}, \lambda, \gamma \mid n_{L}\right)+\gamma v
\end{gathered}
$$

Below I further characterize the solution to this system of equations.

Follower stage: the follower does not engage in innovation, $\gamma_{F}=0$, therefore case B cannot occur and the follower's payoff function, which corresponds to the profit flow, simplifies to:

$$
\pi(p, \lambda)=(1-\tilde{\lambda})\left[\left(1-\tau_{p f} \mathbb{1}_{p>\varsigma_{c}}\right) \Pi_{c}(p)-\tau_{t o}\right]+\widetilde{\lambda} \Pi_{n c}(p)
$$

I first check for corner solutions and then consider interior solutions.

Suppose the firm is fully compliant and chooses $\lambda=0$. Then $\widetilde{\lambda}=0$ and the zero profit condition, $\pi\left(p_{F}, 0\right)=0$, implies $\Pi_{c}(p)>0$, therefore $p_{F}^{0}=$ $\varsigma_{c}\left(1-\tau_{p f}\right) /\left(1-\tau_{p f}-\tau_{t o}\right)$.

Next consider the case where the firm chooses the maximal value of tax evasion. This boundary value is the minimum between $\lambda=1$ and $\lambda:(1+\nu) \operatorname{Pr}(\lambda / p)=$ 1. In the latter case the zero profit condition becomes $\Pi_{n c}(p)=0$, i.e. $p=$ $\varsigma_{n c} /\left(1+\tau_{v a}\right)$. Therefore the maximal value of $\lambda$ in the follower stage is $\bar{\lambda}_{F}=$ $\min \left\langle 1, \bar{\lambda}\left(\frac{\varsigma_{n c}}{1+\tau_{v a}}\right)\right\rangle$ and the optimal price level conditional on this value of $\lambda$ solves $\pi\left(\bar{p}_{F}, \bar{\lambda}_{F}\right)=0$.

Finally consider the case of an interior solution for $\lambda$. The first order necessary condition is:

$$
\begin{aligned}
1-(1+\nu) \operatorname{Pr}\left(\lambda^{i} / p^{i} \mid n_{F}\right)-\lambda(1+\nu) \frac{\partial \operatorname{Pr}}{\partial \lambda}\left(\lambda^{i} / p^{i} \mid n_{F}\right) & =0 \\
\Downarrow & \\
\operatorname{Pr}\left(\lambda^{i} / p^{i} \mid n_{F}\right) & =\frac{1}{(1+a)(1+\nu)} \\
& \Downarrow \\
\widetilde{\lambda}_{F}^{i} & =\lambda^{i} \frac{a}{1+a}=p^{i} \tilde{a}_{n_{F}} \frac{a}{1+a} \\
\tilde{a}_{n_{F}} & \equiv\left[a_{n_{F}}(1+a)(1+\nu)\right]^{-1 / a}
\end{aligned}
$$

where I made use of the fact that $\operatorname{Pr}$ is a power function, $a$ is the exponent and $a_{n_{F}}$ the proportionality coefficient which depends on size. Note that 
$\pi\left(p^{i}, p^{i} \tilde{a}_{n_{F}} \frac{a}{1+a}\right)=0$ becomes a quadratic that can be solved separately for the two cases $\mathbb{1}_{p>\varsigma_{c}} \in\{0,1\}$, and which I denote as $p^{C}$ and $p^{A}$ respectively. It can be shown that in both cases the negative root implies a negative price, thus the relevant root is the positive one. For $p^{i}, i \in A, C$ to be admissible it must be that $\lambda_{F}^{i}<\bar{\lambda}_{F}$, i.e. $p^{i} \tilde{a}_{n_{F}} \frac{a}{1+a}<\min \left\langle 1, \varsigma_{n c} \tilde{a}_{n_{F}}(1+a)^{1 / a}\right\rangle$, and $\Pi_{c}^{\lambda_{F}^{i}, 0}\left(p^{i}\right) \geq 0$ if $i=A$, or $\Pi_{c}^{\lambda_{F}^{i}, 0}\left(p^{i}\right) \leq 0$ if $i=C$.

Then, the leader picks the price $p_{L}=q_{L} p_{F}$ where $p_{F}=\min \left(p_{F}^{0}, \bar{p}_{F},\left\{I_{F}^{A d}\right\}\right)$, $I_{F}^{A d}$ being defined as the set of admissible candidate interior solutions for the price level and it is either empty or contain $p^{A}$ or $p^{C}$ or both. ${ }^{8}$

Leader stage: the leader charges the limit price $p_{L}=q_{L} p_{F}$ and picks $(\lambda, \gamma)$ to maximize:

$$
\pi\left(p_{L}, \lambda, \gamma\right)+\gamma v
$$

Note that if $p_{L}<\varsigma_{c}$ then the firm makes negative profits on the production it reports to the fiscal authority, $\Pi_{c}^{\lambda, \gamma}\left(p_{L}\right)<0, \forall(\lambda, \gamma)$, and only case $\mathrm{C}$ can occur, simplifying the analysis. This is a special case and in general solving the leader problems involves checking for several candidate solutions. Some of these solutions share some components and it is convenient to define:

$$
\begin{aligned}
\lambda_{L}^{i} & =p_{L} \tilde{a}_{n_{L}} \\
\tilde{\lambda}_{L}^{i} & =\lambda_{L}^{i} \frac{a}{1+a} \\
\gamma^{A} & :\left(1-\tau_{p f}\right) \iota^{\prime}\left(\gamma^{+}\right)=v \\
\gamma^{C} & : \iota^{\prime}\left(\gamma^{-}\right)=v \\
\gamma^{0}(\lambda) & : \iota\left(\gamma^{0}(\lambda)\right)=(1-\lambda) \Pi_{c}\left(p_{L}\right)
\end{aligned}
$$

Consider first candidate corner solutions. Suppose the firm is fully compliant and $\lambda=0$. Since $p_{L}$ is known one can compute $\Pi_{c}^{0, \gamma^{+}}\left(p_{L}\right)$, if it is positive then $\left(\lambda=0, \gamma=\gamma^{+}\right)$is a candidate solution. Similarly if $\Pi_{c}^{0, \gamma^{-}}\left(p_{L}\right)<0$ then $(\lambda=$ $0, \gamma=\gamma^{-}$) is a candidate solution. $\gamma^{0}(0)$ is always a candidate solution. The case where the tax evasion choice is maximal is characterized by the same procedure except that $\lambda$ is set equal to the boundary value $\bar{\lambda}_{L}=\min \left\langle 1, p_{L} a_{n_{L}}(1+\nu)^{-1 / a}\right\rangle$. Next, consider the case of an interior solution. If $p_{L}>\varsigma_{c}$, then there are five possible cases, three corresponding to points laying in the interior of the intervals spanned by the conditions $\mathrm{A}, \mathrm{B}$ and $\mathrm{C}$ above and the remaining two corresponding to the two kinks at the intersection between these three segments. In the case of candidate solutions laying in the interior of $\mathrm{A}$ and $\mathrm{C}$ the expression for the profit flow is as in (28a) and the tax evasion choice and the innovation effort choice are locally independent of one another. The corresponding candidates are $\left(\lambda_{L}^{i}, \gamma^{A}\right)$ and $\left(\lambda_{L}^{i}, \gamma^{C}\right)$, provided that $\Pi_{c}^{\lambda_{L}^{i}, \gamma^{A}}\left(p_{L}\right)>0$ and $\Pi_{c}^{0, \gamma^{C}}\left(p_{L}\right)<0$ respectively.

\footnotetext{
${ }^{8}$ It should be that $p^{A}$ and $p^{C}$ cannot be both admissible at the same time though I have not verified it.
} 
Next consider a candidate solution laying in the interior of the segment spanned by condition $\mathrm{B}$. In this case the payoff function can be written as:

$$
(1-\tilde{\lambda})\left[\Pi_{c}\left(p_{L}\right)-\tau_{t o}\right]-\iota(\gamma)+\widetilde{\lambda} \Pi_{n c}\left(p_{L}\right)-(1+\nu) \operatorname{Pr}\left(\frac{\lambda}{p_{L}} \mid n_{L}\right) \tau_{p f}\left[\Pi_{n c}\left(p_{L}\right)-\iota(\gamma)\right]+\gamma v
$$

Then the candidate solution $\left(\lambda_{L}^{B}, \gamma_{L}^{B}\right)$ is characterized by the system of first order conditions:

$$
\begin{aligned}
& \widetilde{\lambda}_{\lambda}\left[\Pi_{n c}\left(p_{L}\right)-\Pi_{c}\left(p_{L}\right)+\tau_{t o}\right]-(1+\nu) \operatorname{Pr}_{\lambda}\left(\frac{\lambda_{L}^{B}}{p_{L}} \mid n_{L}\right) \tau_{p f}\left[\Pi_{n c}\left(p_{L}\right)-\iota\left(\gamma_{L}^{B}\right)\right]=0 \\
&-\iota^{\prime}\left(\gamma_{L}^{B}\right)\left[1-(1+\nu) \operatorname{Pr}\left(\frac{\lambda_{L}^{B}}{p_{L}} \mid n_{L}\right) \tau_{p f}\right]+v=0
\end{aligned}
$$

where, using of the fact that $\operatorname{Pr}$ takes the power form with exponent $a$ :

$$
\begin{aligned}
\widetilde{\lambda}_{\lambda} & =1-(1+\nu) \operatorname{Pr}\left(\frac{\lambda_{L}^{B}}{p_{L}} \mid n_{L}\right)-\lambda_{L}^{B}(1+\nu) \operatorname{Pr}_{\lambda}\left(\frac{\lambda_{L}^{B}}{p_{L}} \mid n_{L}\right) \\
& =1-(1+\nu)(1+a) \operatorname{Pr}\left(\frac{\lambda_{L}^{B}}{p_{L}} \mid n_{L}\right)
\end{aligned}
$$

Then using this expression and further exploiting the functional forms of $\iota$ and Pr, the system of f.o.c. above can be rewritten as:

$$
\begin{aligned}
& {\left[\Pi_{n c}\left(p_{L}\right)-\Pi_{c}\left(p_{L}\right)+\tau_{t o}\right]=}(1+\nu) \operatorname{Pr}\left(\frac{\lambda}{p_{L}} \mid n_{L}\right)\left\{(1+a)\left[\Pi_{n c}\left(p_{L}\right)-\Pi_{c}\left(p_{L}\right)+\tau_{t o}\right]\right. \\
&\left.-\frac{a}{\lambda} \tau_{p f}\left[\Pi_{n c}\left(p_{L}\right)-\iota(\gamma)\right]\right\} \\
& \iota(\gamma)=\left\{\frac{v}{\left(1+\iota_{1}\right)\left[1-(1+\nu) \operatorname{Pr}\left(\frac{\lambda}{p_{L}} \mid n_{L}\right) \tau_{p f}\right]}\right\}^{\frac{1+\iota_{1}}{\iota_{1}}}
\end{aligned}
$$

Finally, I consider the possibility that the solution lays at the kinks. At the conjunction between $\mathrm{A}$ and $\mathrm{B}$, i.e. when $\Pi_{c}^{0, \gamma}(p)>0$ and $\Pi_{c}^{\lambda, \gamma}(p)=0$, the following conditions must hold:

$$
\begin{aligned}
\left(1-\lambda_{L}^{A B}\right) \Pi_{c}\left(p_{L}\right) & =\iota\left(\gamma_{L}^{A B}\right) \\
\left(1-\tau_{p f}\right)\left[-\widetilde{\lambda}_{\lambda} \Pi_{c}\left(p_{L}\right) d \lambda-\iota^{\prime}\left(\gamma_{L}^{A B}\right) d \gamma\right]+\widetilde{\lambda}_{\lambda}\left[\Pi_{n c}\left(p_{L}\right)+\tau_{t o}\right] d \lambda+v d \gamma & =0
\end{aligned}
$$

where the second expression is obtained by totally differentiating the profit function from case $\mathrm{A}$ with respect to $\lambda$ and $\gamma$. Totally differentiating the first expression as well and substituting for $d \gamma$ in the second expression I obtain the following characterization of the candidate solution $\left(\lambda_{L}^{A B}, \gamma_{L}^{A B}\right)$ :

$$
\begin{aligned}
\left(1-\lambda_{L}^{A B}\right) \Pi_{c}\left(p_{L}\right)= & \iota\left(\gamma_{L}^{A B}\right) \\
\Pi_{n c}\left(p_{L}\right)+\tau_{t o}-\frac{\Pi_{c}\left(p_{L}\right)}{\iota^{\prime}\left(\gamma_{L}^{A B}\right)} v= & (1+\nu)(1+a) \operatorname{Pr}\left(\frac{\lambda_{L}^{A B}}{p_{L}} \mid n_{L}\right) \\
& \times\left[\Pi_{n c}\left(p_{L}\right)+\tau_{t o}-\left(1-\tau_{p f}\right) \Pi_{c}\left(p_{L}\right)\right]
\end{aligned}
$$


Similarly, in the case where $\Pi_{c}^{0, \gamma}(p)=0$ and $\Pi_{c}^{\lambda, \gamma}(p)<0$ it must be that:

$$
\begin{aligned}
\Pi_{c}\left(p_{L}\right) & =\iota\left(\gamma_{L}^{B C}\right) \\
\tilde{\lambda}_{\lambda}\left[\Pi_{n c}\left(p_{L}\right)+\tau_{t o}-\Pi_{c}\left(p_{L}\right)\right] d \lambda & =\iota^{\prime}\left(\gamma_{L}^{A B}\right) d \gamma
\end{aligned}
$$

where $\iota^{\prime}\left(\gamma_{L}^{A B}\right) d \gamma=0$ by total differentiation of the first therefore. The candidate solution in this case is $\left(\lambda_{L}^{B C}, \gamma_{L}^{B C}\right)=\left(\lambda_{L}^{i}, \iota^{-1}\left(\Pi_{c}\left(p_{L}\right)\right)\right)$

\section{B The case with no tax evasion: existence, unique- ness and identification}

Suppose $a_{s} \rightarrow \infty$ so that there is no tax evasion, then the model is characterized by the following system equations:

$$
\begin{aligned}
r v & =\pi-\left(1-\tau_{p f}\right) \iota(\gamma \mid w)+\gamma v-\delta v \\
\gamma & =\iota^{\prime-1}\left(\frac{v}{1-\tau_{p f}} \mid w\right) \\
\eta & =m \iota^{\prime-1}(\phi v \mid w) \\
\delta & =\eta+\zeta_{g} \gamma \\
\zeta_{g} & =\frac{\phi \eta}{\delta-\gamma}
\end{aligned}
$$

Where $\pi \equiv\left(1-\tau_{p f}\right)\left[1-\left(1-\tau_{t o}\right) / q\right]-\tau_{t o}$. Under the assumption that $\iota(\cdot)$ takes the power form, $\iota(\gamma)=\left(1+\tau_{l}\right) \iota_{0}^{w} \gamma^{1+\iota_{1}}$ with $\iota_{0}^{w} \equiv w \iota_{0}$, the solution to the system above can be characterized as follows:

$$
\begin{aligned}
\pi & =\left(1-\tau_{p f}\right) \iota(\gamma \mid w)\left[r \frac{1+\iota_{1}}{\gamma}+\xi_{1}+\iota_{1}\left(\xi_{1}-1\right)\right] \\
\eta & =\xi_{0}\left(m, \phi, \iota_{1}\right) \gamma \\
\delta & =\xi_{1}\left(\phi, \xi_{0}\right) \gamma \\
\zeta_{g} & =\xi_{2}\left(\phi, \xi_{0}, \xi_{1}\right) \equiv \frac{\phi \xi_{0}}{\xi_{1}-1} \\
\xi_{0} & \equiv m\left[\phi\left(1-\tau_{p f}\right)\right]^{1 / \iota_{1}} \\
\xi_{1} & \equiv \frac{\sqrt{\left(\xi_{0}-1\right)^{2}+4 \phi \xi_{0}}+\xi_{0}+1}{2}
\end{aligned}
$$

where it can be shown that $\xi_{1}>1$ and, given $w$, (41a) admits one and only one solution, since $\iota_{1}>0$ (so that the LHS monotonically increases from 0 and goes to $\infty$ as $\gamma$ increases from 0 and becomes arbitrarily large). Finally the labor market clearing condition is:

$$
L=\frac{1-\xi_{2}+\xi_{2}[1 / q+\iota(\gamma \mid w)]+m \iota\left(\xi_{0} \gamma / m \mid w\right)}{w\left(1+\tau_{l}\right)}
$$


Note that from (41a) the higher is $w$ the lower is $\gamma$ and that for $w \rightarrow 0$ then $\gamma \rightarrow$ $\infty$ and that for $w \rightarrow \infty$ then $\gamma \rightarrow 0$. As for the labor market clearing condition, it implies a strictly positive relationship between $\gamma$ and $w$. $w$ ranges from to $\left(1-\xi_{2}+\xi_{2} / q\right) / L$ to $\infty, \gamma$ correspondingly varying from 0 to $\bar{\gamma}: \iota_{0}\left[\xi_{2} \gamma^{1+\iota_{1}}+\right.$ $\left.m\left(\xi_{0} \gamma / m\right)^{1+\iota_{1}}\right]$. Then an equilibrium always exists and is unique.

The growth rate and the equilibrium mass of firms are:

$$
\begin{aligned}
\frac{\dot{A}}{A} & =\left(\phi \eta+\zeta_{g} \gamma\right) \ln (q)=\left(\xi_{0}+\xi_{2}\right) \gamma \ln q \\
\theta & =\frac{\eta}{\delta}\left(1-\phi+\phi \xi_{1} \ln \frac{1}{1-1 / \xi_{1}}\right)
\end{aligned}
$$

As argued in section 3 and as it is clear from the equations above the model is identified up to the parameter $\iota_{1}$ only (or $m$ or $\iota_{0}^{w}$ ), if no data on innovation expenditure is available.

A possible strategy for calibration in practice is as follows. First, note that the fraction of firms that exit in an interval $d t$ (small) after entering equals $\delta$ as $d t \rightarrow 0$ and that (43b) can be rewritten as the entry rate, $\eta / \theta$. Also, the growth rate can be used to recover $\ln q$ given knowledge of the other parameters in (43a). Then, given these three statistics, the model can be calibrated according to the following procedure: fix $\xi_{1}$ and recover $\phi$ from (43b). Next, use (40e) to substitute for $\zeta_{g}$ in (40d) and solve for $\eta$. Third, solve (41e) for $m$ and compute $\zeta_{g}$ from (41d). Then $q$ can be recovered from (43a). Finally, the growth rate of surviving firms is a mixture of the process $m_{b}(t)=m_{b}(0) \exp -\delta t$ and a truncated Poisson process with parameters $\gamma$ and $\delta$. Such process can be easily implemented and $\xi_{1}$ tuned so as to match the growth rate of average size with age. This procedure turns out to provide a remarkably good starting point for the more general model with tax evasion.

\section{Additional material}


Table 5: INPS data, descriptive statistics

\begin{tabular}{lrrrrrrrr}
\hline Year & Nr. Firms & \%Firms & \multicolumn{2}{l}{ Wage $($ month.) } & \multicolumn{2}{l}{ Employment } & Entries & Exits \\
& & Manuf. & mean & SD & mean & SD & & \\
1990 & $1,116,992$ & 0.32 & 1102 & 457 & 7.96 & 182.3 & 119,761 & 89,388 \\
1991 & $1,120,621$ & 0.32 & 1217 & 495 & 7.96 & 181.0 & 110,943 & 89,500 \\
1992 & $1,122,468$ & 0.31 & 1288 & 539 & 7.86 & 188.1 & 108,285 & 101,587 \\
1993 & $1,084,614$ & 0.31 & 1334 & 556 & 7.80 & 184.2 & 92,043 & 98,763 \\
1994 & $1,059,329$ & 0.31 & 1382 & 579 & 7.83 & 180.2 & 94,419 & 81,301 \\
1995 & $1,063,816$ & 0.30 & 1441 & 620 & 7.87 & 179.1 & 99,008 & 80,571 \\
1996 & $1,069,946$ & 0.30 & 1492 & 646 & 7.94 & 172.9 & 99,307 & 84,649 \\
1997 & $1,058,116$ & 0.30 & 1550 & 670 & 7.96 & 163.1 & 94,745 & 76,463 \\
1998 & $1,082,872$ & 0.29 & 1580 & 697 & 7.97 & 156.2 & 106,450 & 75,046 \\
1999 & $1,136,162$ & 0.28 & 1595 & 711 & 7.86 & 138.3 & 128,635 & 82,627 \\
2000 & $1,181,332$ & 0.27 & 1637 & 766 & 7.97 & 139.1 & 132,294 & 88,274 \\
2001 & $1,222,383$ & 0.27 & 1675 & 821 & 7.98 & 140.1 & 137,106 & 90,527 \\
2002 & $1,293,290$ & 0.26 & 1693 & 788 & 7.73 & 133.2 & 155,194 & 94,486 \\
2003 & $1,325,115$ & 0.25 & 1728 & 819 & 7.70 & 130.0 & 125,665 & 106,940 \\
2004 & $1,369,569$ & 0.24 & 1765 & 837 & 7.59 & 127.9 & 144,785 & 119,100 \\
2005 & $1,380,837$ & 0.24 & 1816 & 892 & 7.56 & 128.7 & 135,505 & 123,533 \\
2006 & $1,403,806$ & 0.23 & 1872 & 938 & 7.55 & 132.0 & 146,537 & 122,250 \\
2007 & $1,474,110$ & 0.22 & 1898 & 994 & 7.53 & 133.5 & 176,132 & 135,930 \\
2008 & $1,496,808$ & 0.22 & 1973 & 1030 & 7.57 & 129.0 & 155,171 & 149,387 \\
2009 & $1,478,586$ & 0.22 & 1975 & 1006 & 7.48 & 146.9 & 135,234 & 147,925 \\
2010 & $1,471,068$ & 0.21 & 2031 & 1055 & 7.43 & 169.6 & 139,684 & 140,797 \\
2011 & $1,467,732$ & 0.21 & 2068 & 1070 & 7.46 & 165.1 & 137,296 & 146,722 \\
2012 & $1,468,611$ & 0.21 & 2073 & 1086 & 7.35 & 167.6 & 139,508 & 162,870 \\
2013 & $1,414,664$ & 0.21 & 2100 & 1139 & 7.44 & 169.1 & 118,601 & 159,614 \\
\hline
\end{tabular}

Non-agricultural business sector, universe of employer businesses. SD $=$ standard deviation. Source: social security administrative register. 